\title{
FISCALIDAD E INDEPENDENCIA EN SANTAFÉ Y BOGOTÁ, $1780-1830$
}

\section{TAXATION AND INDEPENDENCE IN SANTAFE AND BOGOTA, 1780-1830}

\author{
José Joaquín Pinto Bernal \\ Universidad del Tolima, Ibagué, Colombia, \\ jjpintob@ut.edu.co
}

\begin{abstract}
Resumen. El artículo analiza los cambios del fisco de Santafé y Bogotá entre 1780 y 1830 por medio del estudio de las variaciones en la política fiscal, la estructura y dinámica de ingresos y gastos. Este análisis asumió el comportamiento de las series fiscales como consecuencia directa de las condiciones en la estructura política y económica en Colombia. Se evaluaron los resultados de la política fiscal con base en series cuantitativas del comportamiento de ingreso y egreso, al demostrar que el proceso independentista mantuvo parte del sistema impositivo colonial con pequeños cambios referentes a un mayor uso del crédito, de recursos eventuales y aumento del gasto militar, permaneciendo el carácter patrimonial de la Hacienda de la capital.
\end{abstract}

Palabras clave: Colombia; historia económica; tributación; series cuantitativas.

Abstract. The article analyzes the changes in the tax structure in Santafe and Bogota between 1780 and 1830 through the study of changes in fiscal policy and in the structure and dynamics of income and expenditure. This analysis assumed behavior of the series as a direct result of the conditions of political and economic structure. So, it was possible to evaluate the results of fiscal policy based on quantitative series of income and expenditure showing that the independence process maintained the colonial tax system with minor changes relating to increased use of credit and a growing increase in military spending, remaining the patrimonial character of the income structure of the capital.

Key words: Colombia; economic history; taxation; quantitative series.

Fecha de recepción: 25 de mayo de 2014. Fecha de aceptación: 3 de octubre de 2014.

Am. Lat. Hist. Econ., año 22, núm. 3, septiembre-diciembre, 2015, pp. 7-43 


\section{INTRODUCCIÓN}

$\mathrm{E}$ ntre la segunda mitad del siglo XVIII y la primera del XIX, América sufrió importantes cambios políticos, económicos y sociales marcados por la reorganización del aparato de gobierno metropolitano, la consecución de la independencia y la formación de los Estados nacionales. En el ámbito fiscal, los cambios no pudieron ser menores, puesto que para la época la corona española y las administraciones de las nuevas repúblicas buscaron la consecución de recursos para consolidar los Estados como órganos capaces de controlar el monopolio fiscal y coactivo.

Este proceso tuvo su génesis en los intentos de los Borbones por consolidar el Estado fiscal militar español, concepto acuñado por Brewer (1990) para caracterizar el conjunto de instituciones fiscales que se manifestaron en Europa durante el periodo de transición entre el Estado patrimonial y el fiscal. De esta forma, la modernización del fisco fue evidente al final del periodo en los Estados que recaudaron sus ingresos en forma monetaria, con un dominio total de la imposición para depender de la extracción de fondos provenientes de actividades económicas privadas y abandonar el carácter patrimonial de las Haciendas del antiguo régimen (Yun-Casalilla, 2012).

La conformación del Estado fiscal militar fue principalmente estimulada por la guerra entre las potencias coloniales, provocada por la búsqueda de ventajas en el comercio exterior para fomentar el desarrollo económico en las metrópolis (Wallerstein, 1984). El éxito económico dependía del triunfo en la guerra, el cual estaba altamente condicionado por la disponibilidad de recursos fiscales para su financiamiento, razón por la que se buscó consolidar el monopolio fiscal y militar (Schnerb, 1973). Por lo tanto, la guerra imperial y el monopolio comercial cumplen un papel preponderante para la compresión del desarrollo del fisco entre los siglos XVIII y XIX (Yun-Casalilla, 2012).

Inglaterra se constituyó como ejemplo clásico de un Estado fiscal militar sólido, caracterizado por contar con un amplio desarrollo bélico, un elevado gasto militar, un sistema de deuda consolidado, un constante crecimiento del ingreso fiscal, una estructura impositiva fundada en las actividades económicas privadas, una fuerte estructura administrativa y paz interna (Storrs, 2009), caso contrario al de España que intentó afianzar el Estado fiscal militar después del ascenso de los Borbones al trono, obteniendo un éxito escaso (Torres, 2007). Tal y como lo demostró González (2008), existe una diferencia fundamental entre el modo de financiamiento y el esfuerzo bélico en Inglaterra y España. Mientras los ingleses sustentaron su empresa en el crédito otorgado del sector mercantil, el que por medio de la guerra amplió sus mercados y acumuló mayores ganancias que podían ser reinvertidas en una economía que brindaba respeto a la 
propiedad privada, en España la guerra fue financiada por prestamistas que buscaron asegurar puestos dentro de la administración metropolitana, lo que dificultó las reformas administrativas necesarias para consolidar el Estado fiscal militar.

Este proceso no sería ajeno a la América española, indispensable en el proyecto de consolidación del Estado fiscal militar español a través de la implementación de lo que Lynch (1983) llamó el nuevo imperialismo, llevado a cabo por la reorganización administrativa, la eliminación de los privilegios corporativos, la instauración de monopolios productivos y la liberación del comercio. Posterior a ello, la independencia y los nuevos Estados nacionales no abandonaron el proyecto de modernización del fisco iniciado por los Borbones, ya no con la finalidad de construir aparatos militares para dominar el comercio transatlántico y convertirse en potencias coloniales, sino la consolidación de los nacientes Estados, empresa que fue afectada por el desarrollo de las guerras internas y el desempeño de sus actividades productivas. Este recorrido teórico permite hacer presentes dos variables fundamentales para el desarrollo del presente trabajo: $a$ ) las guerras entre colonias y la de independencia, y $b$ ) el desarrollo de las actividades productivas, como ya lo habían reconocido Alves y Sánchez (2012).

Este artículo muestra el proceso que tuvo el fisco de la ciudad de Bogotá entre 1780 y 1830 , producto del comportamiento de las actividades productivas y el desarrollo de la guerra, entre potencias y en el ámbito interno. Es preciso aclarar que no se hará un análisis exhaustivo de las repercusiones políticas y económicas que el fisco tuvo para la capital andina, al respecto sólo se plantearán algunas hipótesis que contribuyan a la presente línea de investigación. En palabras de Schumpeter (2000), se estudiará al fisco como efecto de los ámbitos político y económico.

Partimos de la premisa de que el desarrollo de la guerra (externa o interna) determinó los objetivos de la política fiscal, misma que tuvo resultados medibles, en términos cuantitativos, a través del análisis de las series de ingreso y egreso que dependieron a su vez del desarrollo de la confrontación armada y su impacto sobre la estructura administrativa y las actividades productivas. En tal sentido, este artículo responde a las siguientes preguntas: ¿cómo el desarrollo de la guerra afectó el diseñó de la política fiscal en Santafé y Bogotá entre 1780 y 1830?, y ¿cuáles fueron los resultados cuantitativos de la política fiscal instituida en Santafé y Bogotá en este periodo? El abordaje de tales cuestionamientos dará cuenta de la guerra como factor preponderante en la imposibilidad de la modernización del fisco santafereño.

Para tal fin se ha optado por el modelo de análisis que propuso Ardant (1975), el cual parte del estudio de la política impositiva determinada por los objetivos de gobierno y condicionados por la guerra y el desarrollo de 
las actividades productivas; esta tiene resultados específicos en lo político y lo económico, aspectos que determinan el mantenimiento o el abandono de las disposiciones fiscales, para reiniciar el ciclo de su formulación. De tal manera, es necesario caracterizar la guerra y sus repercusiones en la estrategia fiscal diseñada para la capital andina, analizar las dinámicas de ingreso y egreso como producto de la situación económica y política de cada momento, y por último mostrar cómo los resultados cuantitativos hicieron de nuevo reorientar los objetivos de gobierno, la estructura impositiva y de asignación.

La historiografía fiscal que se ocupa del estudio de la región de Santafé y Bogotá durante la segunda mitad del siglo XVIII y la primera del XIX es reciente, a pesar del gran número de trabajos que abordan la problemática para otras ciudades latinoamericanas como Buenos Aires (Halperin, 2005), Caracas (Carrillo, 1998) y México (Marichal y Carmagnani, 2001). Las principales dificultades para abordar la historia fiscal de Santafé y Bogotá radican en la inexistencia de series fiscales completas publicadas para el periodo colonial y la creciente dificultad que implica la reconstrucción de las mismas para el periodo independentista y el temprano republicano.

Para la región de Santafé sólo se conocen los ingresos totales de la Caja Real entre 1790 y 1807, así como la composición de dichos ingresos para algunos años aleatorios (Arévalo, Fresneda, Chaparro y Rodríguez, 2009). Para el periodo comprendido entre 1803 y 1815 se cuenta con los promedios anuales de ingreso por ramos (Muñoz, 2010), el periodo de la reconquista es abordado en otro trabajo donde no se puede hablar de la reconstrucción de series totales, sino tan sólo de años parciales (Díaz, 2013), mientras que para el periodo de la Gran Colombia se cuenta con las series completas (Pinto, 2011). El presente trabajo aporta las series de ingresos y egresos fiscales más completas y conocidas hasta el momento de Bogotá entre 1780 y 1830, y organizadas con base en el método empleado por Klein (1973), donde los ingresos son agrupados de acuerdo con la actividad económica de la que provengan y los egresos según la finalidad civil, militar o financiera a la que estén determinados.

Las cifras sobre las que se fundamentan el análisis estadístico y los gráficos se encuentran en el anexo (véanse cuadros 1 y 2), mismas que constituyen una pieza central para desarrollos futuros. Las fuentes son los Sumarios Generales de Cargo y Data de la Caja Real de Santafé, del Archivo General de la Nación de Colombia y de la David M. Rubenstein Rare Book \& Manuscript Library de la Duke University compilados por John Jay TePaske. Las cifras del periodo de 1819 a 1830 fueron extractadas de la reconstrucción en Pinto (2011), la cual se realizó con base en la prensa y los cuadros de Estados Generales de la Tesorería de Bogotá del Archivo General de la Nación de Colombia. 
El artículo analiza la política fiscal y sus resultados en la capital andina entre 1780 y 1830 , con base en una periodización que prioriza los cambios institucionales como criterio principal para su determinación: 1780-1809, periodo tardío colonial; 1810-1816, periodo de la soberanía local; 18161819, periodo de la reconquista española, y 1819-1830, conformación y finalización de la República de Colombia. Cada uno de estos periodos está desarrollado en una sección, en las que se explican las razones de la adopción de la política fiscal en relación con la situación económica y política manifestada en la capital.

A continuación se muestran los resultados de dichas políticas por medio del análisis de las series de tiempo con base en la determinación de la pendiente de la ecuación de regresión lineal en términos globales y sectoriales calculada a través del método de mínimos cuadrados ordinarios, para por último comprobar cómo dichas tendencias generaron la trasformación del arreglo institucional o el cambio en la política fiscal.

\section{La Caja Real de Santafé, 1780-1809}

Desde comienzos del siglo XVIII la monarquía española se mostraba preocupada por la centralización de la administración de sus rentas, esto con el fin de hacer frente a los gastos de las guerras que frecuentemente se presentaban contra sus competidoras por la hegemonía en el comercio atlántico. Felipe $\mathrm{V}$ buscó a través de los decretos de nueva planta centralizar las finanzas, eliminar las diferencias debido a las particularidades provinciales y lograr la estabilidad monetaria (Comín y Yun-Casalilla, 2012), y así institucionalizar la Secretaría del Despacho Universal como máxima instancia del ejecutivo (Dieu, 2009). Sin embargo, internamente, los proyectos nunca llegaron a consolidarse de forma total. Según Angulo (2000), los obstáculos a tales objetivos se encuentran en el fracaso de algunas medidas impuestas por la corona para incrementar sus ingresos fiscales, y que dependían en primera instancia de los fondos de Castilla incluidos las remisiones de Indias, los demás reinos y la Iglesia. Aunque el rey y los ministros de la Secretaría Universal aplicaron medidas como la equiparación de los reinos, la supresión del arrendamiento de las rentas o la implementación de la contribución única durante todo el siglo XVIII, sus esfuerzos no dieron frutos, principalmente por la falta de uniformidad fiscal entre los territorios y a que otros agentes distintos a la burocracia, como la Iglesia y los señores territoriales, ejercieron el poder de recaudar.

A pesar del fracaso en la formación de un sólido Estado fiscal militar, es claro que la política metropolitana se orientó a consolidar una mayor centralización y control de los recursos fiscales, con el fin de fortalecer 
su ejército y armada para hacer frente a las guerras, lo cual le permitiría asegurar el predominio comercial en el Atlántico y fomentar mejores rendimientos en la economía metropolitana. Con base en estos objetivos, el ministro de gobierno, Joseph del Campillo y Cossio, diseñó una política especial para América, en la que se prefiguraban los medios para que las colonias participasen de forma activa en el proyecto de conformación del Estado fiscal militar español, política que se conoce en la historiografía bajo el nombre de reformas borbónicas.

El proyecto de Campillo partía de una constatación fundamental: "Debemos mirar la América bajo de dos conceptos. El primero, en cuanto puede dar consumo a nuestros frutos y mercancías; y el segundo, en cuanto es una porción considerable de la monarquía, en que cabe hacer las mismas mejoras que en España" (Campillo, 1784, p. 8). La realización de esta política tuvo que sortear obstáculos estructurales como el contrabando, las manufacturas americanas y la evasión fiscal, razones por las que se promulgó la política de libre comercio con las Américas, la reorganización administrativa del fisco y la creación de monopolios estatales a la producción de bienes manufacturados y agrícolas con una alta cotización en el mercado externo. Los fines últimos de la política fiscal metropolitana fueron estimular la producción metropolitana, aumentar el recurso fiscal para construir un sólido sistema de defensa en América y la metrópoli.

Para algunos trabajos los resultados de la política fiscal en América no fueron tan amplios como normalmente se asume, debido a que se impuso un marco de negociación generalizado entre las elites criollas y el gobierno metropolitano (Irigoin y Grafe, 2008), sistema en el cual los criollos reconocieron al rey como único árbitro de última instancia para la resolución de sus reclamos; esta situación disminuyó los resultados benéficos de las reformas fiscales para la economía metropolitana, objetivo que fue rezagado a un segundo plano, como lo muestra la adopción del comercio con neutrales y colonias extranjeras no para beneficiar el sector manufacturero español, sino para evitar la bancarrota de la corona en el ocaso del reinado de Carlos IV (Barbier, 1980). A pesar de lo anterior es imposible negar el papel central que tuvieron las remisiones de América a España y la importancia de los situados para la consolidación del sistema de defensa colonial, factor que no sólo buscaba asegurar el dominio de la corona en las costas, sino fundamentalmente hacer frente a los conflictos con las potencias para asegurarse el monopolio comercial americano.

A pesar del carácter compuesto de la monarquía y desaprovechamiento de las remesas americanas para el desarrollo económico metropolitano, las colonias eran indispensables para el sostenimiento de la monarquía española, como lo demuestra el hecho de que las remesas de Indias fueron parte integrante de los fondos de la corona de Castilla, al representar el 
19\% de los ingresos totales en el periodo comprendido entre 1763 y 1811. Esta participación igualó en 1802 los ingresos ordinarios originados en España y en el periodo 1808-1809 superó a estos (Marichal, 1999).

Asimismo, las reformas borbónicas reorganizaron la distribución de los rendimientos fiscales en América para la consolidación del sistema de defensa, fundamental a los fines políticos y económicos de la monarquía; también configuraron un proceso de "regionalización tributaria de las remesas" (Jara, 2011) en el que las cajas principales de México, Quito, Santafé, Lima y Buenos Aires cumplían tareas específicas de abastecimiento de recursos para el mantenimiento del aparato militar, estableciendo así cuatro regiones.

Jara (2011) ha mostrado la composición de tales regiones. Las responsabilidades de Nueva España abarcaban el envío de recursos para el norte, las dos vertientes oceánicas del virreinato novohispano, Filipinas, Guatemala, Yucatán, isla del Carmen, Panamá, Nueva Granada, Cuba, Puerto Rico, Santo Domingo, isla Trinidad y Cumaná. El otro frente de defensa fue el sur del Caribe, el cual era suplido por las remisiones de Nueva España en el caso de Cumaná y Trinidad (Marichal, 1999), Santafé y Quito para suplir Cartagena y Guayana. La otra zona de defensa estaba conformada por el sur del Pacífico, específicamente las plazas de Panamá, la zona costera de Perú y Chile, obligaciones que fueron suplidas por el virreinato limeño. La última región es la correspondiente a la defensa de la frontera portuguesa y el litoral Atlántico sur, labor para la cual fue creado el virreinato del Río de la Plata en 1776 y cuyo principal centro de redistribución de fondos fue la Caja Real de Buenos Aires.

La importancia de América en el sostenimiento de España y el sistema de defensa colonial creció gracias a la centralización y buenos rendimientos que los ingresos fiscales mostraron en Nueva España al menos hasta 1780 con base en los monopolios como fuente principal de ingreso (Klein, 1994); Perú con los tributos a la cabeza de su recaudo (Klein, 1994); Buenos Aires con base en sus recaudos aduaneros (Halperin, 2005), y Nueva Granada sustentada con los rendimientos de los estancos de tabaco y el aguardiente (Meisel, 2011).

Santafé, como capital del virreinato de Nueva Granada, fue esencial al financiar la defensa del sur del Caribe, razón por la que fue enviado Juan Francisco Gutiérrez de Piñeres como encargado de establecer las reformas puntuales en pro de la consecución de los fines metropolitanos. Es sabido que la consolidación de los monopolios, la separación del cobro de la alcabala respecto al derecho de la Armada de Barlovento y el aumento del precio del aguardiente provocaron el inicio de la rebelión de los comuneros, movimiento que se caracterizó por reclamos centrados en la flexibilización de la política comercial y fiscal, tal y como lo manifiesta el hecho 
de que 18 de 36 capitulaciones firmadas por los representantes de la Real Audiencia en Santafé tuviesen como principal objetivo la destrucción de la mayor parte del aparato fiscal (Friede, 1981).

A pesar del caos generado por la revuelta, la corona logró reconstituir el orden al invalidar las capitulaciones, al tiempo que ajustició a los revoltosos y consolidó los resultados de la gestión de Gutiérrez, los cuales permitieron consolidar a Santafé como centro político y administrativo, con muy buenos resultados en términos de recaudo fiscal gracias a la reorganización del tribunal mayor de cuentas, el fortalecimiento de la administración principal de alcabalas y de rentas estancadas, así como de la Junta Superior de Hacienda (Rodríguez, 1983).

Para finales del siglo XVIII, Nueva Granada gozaba de un creciente mejoramiento de la economía manifestado en el aumento de la producción aurífera (Jaramillo, 2007), el crecimiento de la población (Meisel, 2011) y el incremento de las exportaciones (Bohórquez, 2009), factores que ocasionaron que el producto interno bruto (PIB) creciese considerablemente hasta 1800 (Meisel, 2011). Santafé también se benefició, pues en el marco de la economía colonial neogranadina cumplió funciones de centro comercial para la circulación de bienes a larga distancia entre las zonas mineras y los puertos, y a corta distancia a través del tráfico de bienes primarios para la región central (Muñoz, 2012). Además, la producción agrícola medida por medio de los remates de diezmos mostró un considerable incremento registrando pendientes de regresión lineal de 5727 pesos entre 1780 y 1789, y de 7731 pesos entre 1790 y 1799 (Brungardt, 1983). Igualmente, Santafé era uno de los principales centros de acopio de oro al contar con la Casa de Moneda, la cual registró series de amonedación al alza con pendientes de regresión lineal de 14400 pesos entre 1780 y 1789, y de 38474 pesos entre 1790 y 1799 (Torres, 2012).

Sin embargo, recientes investigaciones (Torres, 2012 y 2013) determinan que en la última década colonial, entre 1800 y 1809, la economía granadina y santafereña mostró rendimientos negativos. Las señales de tal situación se encontraron en la retracción de la producción minera, manifestada en la pendiente de regresión lineal de la amonedación en Santafé con un valor de menos 3334 pesos (Torres, 2012). La razón de tal circunstancia fue el encarecimiento de los costos de producción aurífera, provocado por la sobreoferta de metálico debido a la imposibilidad de su extracción hacia el exterior (Torres, 2013). Por ello, la demanda de bienes de consumo por parte de los centros mineros disminuyó, afectando la demanda de tabaco y de bienes agrícolas del centro y los rendimientos de la Casa de Moneda.

Tres décadas comprenden el horizonte de esta indagación, marcadas por una política fiscal orientada a la centralización y vigilancia del recaudo a favor de su aumento paulatino, fondos que debían ser destinados a los 
gastos propios de la administración del virreinato, además de contribuir a la consolidación del sistema de defensa en el sur del Caribe a través de situados a Cartagena. Dichas medidas serían aplicadas con base en un aparato productivo creciente entre 1780 y 1799, el cual para la última década de dominio colonial mostraba síntomas de rezago. En este marco evaluaremos los resultados de las políticas implantadas bajo un análisis de las series globales de ingresos y egresos en la Caja Real.

El ingreso global de la Caja Real de Santafé (excluyendo las remisiones de otras cajas y el crédito) muestra el éxito progresivo de la política fiscal centralizadora para el aumento del recaudo, ya que registra una pendiente de la ecuación de la recta con un valor de 9445 pesos entre 1780 y 1789, y de 72999 pesos entre 1790 y 1799. La composición de tales ingresos se sustentó fundamentalmente en los monopolios con 39\% del total recaudado, seguido por los impuestos al clero con 17\%, los ingresos de la masa común con $13 \%$, los impuestos comerciales con $12 \%$, la minería con $12 \%$, la agricultura con $7 \%$ y los descuentos a sueldos civiles y militares con $3 \%$, ramos que mostraron tendencias al alza en las dos décadas a excepción de los impuestos al clero que tendieron a la baja entre 1790 y 1799 .

Por otra parte, cabe mencionar que Santafé tenía como una de sus obligaciones concentrar los sobrantes de cajas distantes para el mantenimiento de la burocracia virreinal, para cubrir los déficits de cajas subalternas o para remitir fondos a Cartagena como pieza clave en el sistema de defensa imperial. En este aspecto también las reformas administrativas mostraron buenos resultados, de hecho Santafé se constituyó como centro de acopio de fondos provenientes de una vasta región que abarcó Antioquia, Popayán, Chocó, Mompox, Cartago, Cartagena, Pamplona, Honda, Remedios, Girón, los Llanos e Ibagué en Nueva Granada; además cubrió territorios distantes como Quito y Panamá, lo cual contradice la hipótesis de Arévalo (2011) quien formula la inoperancia en términos administrativos del virreinato para el caso de Panamá. Esta labor de acopio mostró una tendencia a la baja durante la primera década de estudio; sin embargo, entre 1790 y 1799 la pendiente de la ecuación de la recta arrojó 5652 pesos.

Las reformas administrativas para el aumento y la centralización del ingreso en Santafé dieron buenos resultados entre 1780 y 1799; sin embargo, no fueron suficientes para hacer frente a los gastos propios y para suplir otras cajas, fenómeno que se aclara si se analiza el gasto.

Los egresos muestran la importancia de Santafé entre 1780 y 1789 como centro político-administrativo y como ente encargado de la redistribución de los ingresos fiscales para la consolidación del sistema de defensa en Cartagena y Panamá. Al ser centro político, Santafé invirtió en ese periodo $47 \%$ del total de sus erogaciones en la administración civil con una pendiente de 29987 pesos, rubro que fue seguido por las remi- 
siones a otras tesorerías con $26 \%$ del total, pero con pendiente de menos 1771 pesos. Los gastos militares constituyeron $18 \%$ con un incremento de 7291 pesos, los eclesiásticos reportaron $7.5 \%$ con tendencia al alza y el crédito, $2.9 \%$ a la baja. Las cifras de gasto evidencian la reorientación de las prioridades de este hacia la consolidación de la administración civil.

Los gastos de la caja entre 1790 y 1799 revelan la preponderancia de atención a las funciones de administración civil propias en la capital virreinal con 69\% del total y con una pendiente de 89804 pesos. Asimismo, los buenos rendimientos de ingreso permitieron que Santafé reactivara su participación como centro encargado de la redistribución de los ingresos fiscales para su remisión a España o a Cartagena, rubro que registró 16\% del total con una pendiente de 4434 pesos. El gasto militar disminuyó su participación a tan sólo 7\%, debido a la estabilidad política registrada en el periodo. Por su parte, los gastos eclesiásticos tendían a la baja con una participación de 5\%, así como el servicio de deuda con $2.8 \%$ del total.

Al comprobar esta dinámica y comparar los egresos totales con los ingresos ordinarios, sumando las remisiones de otras tesorerías, es evidente que en términos fiscales las reformas administrativas y sus buenos resultados en los ingresos entre 1780 y 1799 no fueron del todo exitosas, pues el déficit estuvo presente en varios años, llegando incluso a un considerable volumen para 1799 (véase gráfica 1). Para poder solventar el déficit, el gobierno virreinal optó por contratar préstamos internos, los cuales ascendieron a 988554 pesos entre 1780 y 1799; desafortunadamente los documentos no permiten evaluar el origen de dichos fondos.

Si para los años corridos entre 1780 y 1799 el éxito de transformar a Bogotá en el bastión para la centralización del ingreso y para el aprovisionamiento de los puestos de defensa en el Atlántico fue relativo, en la medida en que el ingreso tendía al alza, entre 1800 y 1809 el panorama se nubló como producto de la caída o estancamiento de algunas fuentes de ingreso, así como por el aumento del gasto civil en la propia región santafereña, lo que hizo imposible la remisión de fondos a otras tesorerías.

Si se toma en cuenta que entre 1800 y 1809 la estabilidad política reinó al interior del virreinato, lo que implicó el mantenimiento de la estructura administrativa, las causas de la caída del ingreso deben buscarse en el comportamiento de las actividades productivas de la región central. En efecto, la pendiente de remates de diezmos muestran una desaceleración considerable del crecimiento respecto a las dos décadas anteriores (Brungardt, 1983), misma situación que refleja la pendiente de la serie de amonedación (Torres, 2012). Ambas cifras muestran el inicio de una coyuntura de crisis para la agricultura y la minería en la región central, la cual sería avivada por los estragos durante el cierre de puertos, producto de la guerra contra Inglaterra. 


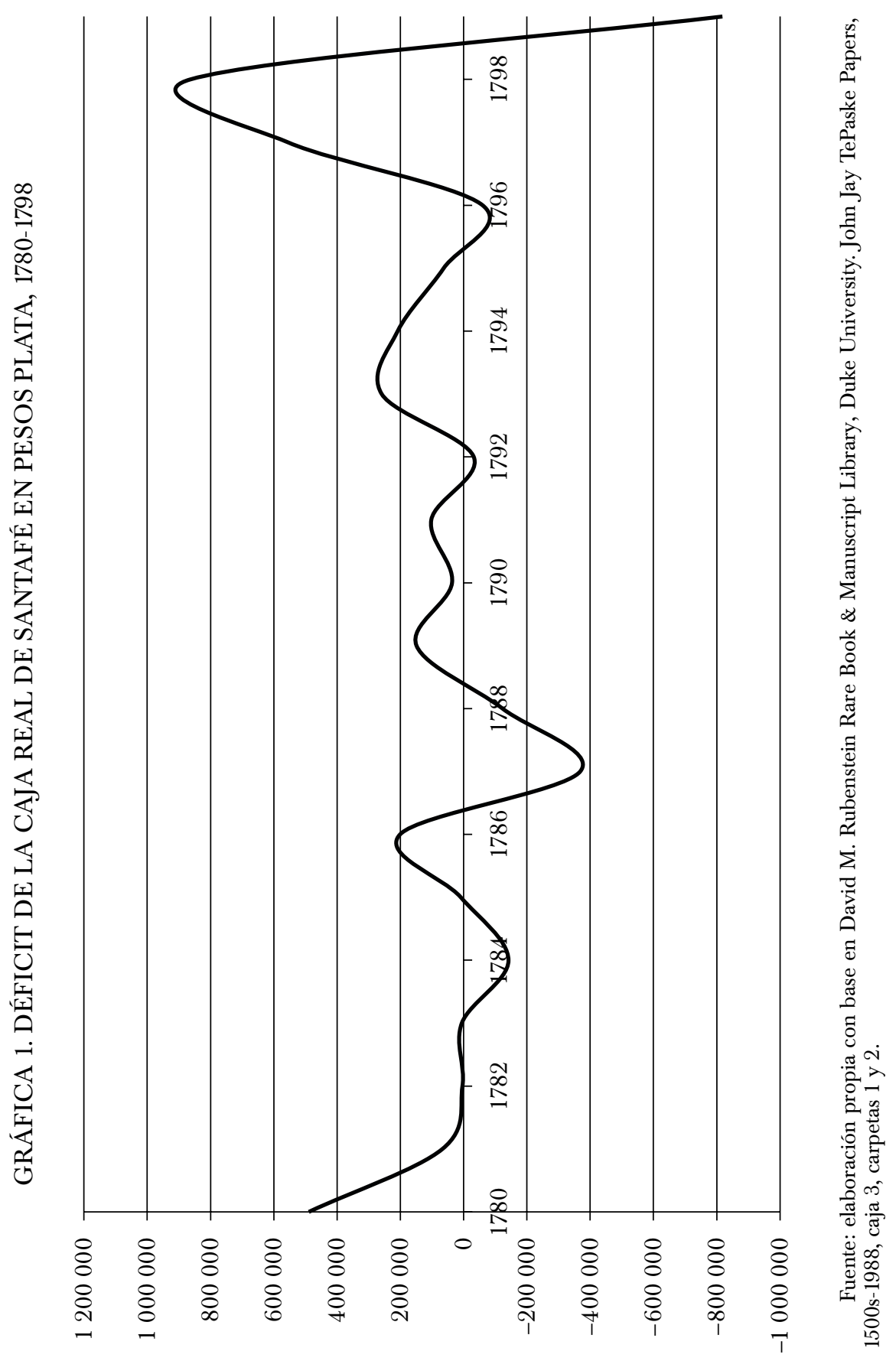


El análisis de las cifras de ingreso confirma la situación al registrar una pendiente de regresión lineal de menos 4441 pesos. Las pendientes de la ecuación de la recta muestran tendencias a la baja en los impuestos al clero, la minería, la agricultura y los monopolios, rubros que suman $68 \%$ del total de los ingresos ordinarios. Los impuestos misceláneos muestran disposición al alza, para constituirse en el segundo rubro de importancia con 17\% del recaudo con la venta de bienes estatales; los descuentos a empleados muestran una leve pendiente de 534 pesos, mientras los impuestos comerciales crecieron a un ritmo similar al de la década corrida entre 1790 y 1799.

De esta forma se pueden lanzar varias hipótesis para explicar tales comportamientos, a saber: a) la reducción de emisiones en la Casa de Moneda -como producto de la crisis en el sector minero- generó la tendencia a la baja en los impuestos a dicha actividad; $b$ ) la administración general de tabacos (principal monopolio de la ciudad) satisfacía la demanda de la región minera, por lo tanto, la reducción de sus rendimientos pudo deberse a una retracción de la demanda en las regiones productoras del metal; c) la desaceleración del crecimiento de la agricultura en la región central es la razón de la caída en los rendimientos de impuestos a dicha actividad, y $d$ ) la caída de los ingresos provenientes del clero se produce por los malos rendimientos de los bienes de temporalidades, algunos de los cuales se dedicaban a la producción agrícola.

Estas hipótesis deben corroborarse por futuras investigaciones que centren su atención en el análisis sectorial de cada rubro, labor que sobrepasa los alcances del presente trabajo, que aporta una mirada general del fisco santafereño, aspecto irrealizado hasta el momento. Sin embargo, considero que es el deterioro de las actividades productivas el que lleva a la caída de los ingresos en Santafé entre 1800 y 1809 al no presentarse variaciones significativas de las alícuotas impositivas o desórdenes internos para estos años.

La situación se agravó ante la baja de los ingresos provenientes de las actividades económicas en la región, puesto que las remisiones de otras tesorerías no llegaron para los años de 1801, 1802 y 1804, manteniéndose en declive, la razón de este comportamiento es aún tema de análisis y sería menester reconstruir el ingreso de todas las cajas del virreinato para comprenderla a cabalidad; desafortunadamente la historiografía colombiana aún no desarrolla tal trabajo. Ante este panorama no es difícil comprender cómo para el año de 1803 se registró la mayor suma de ingresos crediticios para llegar a más de 103000 pesos con déficits que rebasaron los 200000 pesos.

La disminución de ingresos afectó los gastos, con tendencia a la baja en la administración civil, lo que significó 79\% de las erogaciones en los gastos eclesiásticos y en la inversión de fondos en el servicio de deuda. Por otra parte, se manifestó una desaceleración significativa del incremento de 
las remisiones a otras tesorerías, además de que por primera vez tienden a crecer los gastos militares en razón a la incertidumbre generada después de 1808, tras la abdicación del rey.

La dinámica de ingreso y egreso en el fisco santafeño refleja que para la última década de dominio colonial la Caja Real no pudo cumplir a cabalidad con sus dos principales objetivos: a) mantener la administración central del virreinato, y $b$ ) remitir fondos para la consolidación de la defensa en el sur del Caribe. La causa de tal incumplimiento no se debió a la inoperancia de la administración centralizada, implantada desde 1780, ya que esta rindió buenos resultados entre 1780 y 1799, sino a la caída o estancamiento de los ramos ordinarios de ingreso provenientes de diversas actividades económicas, lo cual se puede explicar al constatar el deterioro en los rendimientos de la agricultura y la minería en la región central.

En este contexto, la elite criolla era consciente de que el cierre de puertos significaba la reducción de sus utilidades comerciales, generaba el aumento de los precios en los mercados locales deteriorando la producción minera y por lo tanto la demanda de bienes de consumo para cada uno de los distritos. Por tales razones inició una fuerte crítica al fisco colonial, se pedía la eliminación de las alcabalas, los resguardos, los tributos y los monopolios, tal y como lo hiciesen en 1781 los comuneros (Ocampo, 1999). Así lo harían Antonio Nariño (1990), quien propuso la derogación de gran parte del aparato fiscal colonial en 1797, y José Ignacio de Pombo (1965) para quien la reactivación económica no sólo dependía de la disminución de la presión fiscal, sino de la necesaria flexibilización de la política comercial metropolitana para permitir el comercio con neutrales y colonias extranjeras en épocas de guerra entre las potencias, discusión que estuvo presente en Nueva Granada al menos desde 1778 (Bohórquez, 2014).

A pesar del deterioro económico, la reducción de los ingresos fiscales y la creciente tensión social presente en los reclamos cada vez más airados de los criollos, la corona no se mostró a favor del comercio con neutrales y colonias extranjeras para desmontar algunos gravámenes coloniales, pues las autoridades metropolitanas argumentaban la necesidad de los fondos para solventar la guerra (Arévalo, 2011). Las demandas de los criollos caían en manos del gobierno metropolitano, quien no las plasmó en los proyectos legislativos que debían ser aprobados por el rey como árbitro de última instancia reconocido por los americanos (Irigoin y Grafe, 2012); ante este hecho, la elite criolla se sentía maniatada pues su participación política estaba reducida a los cabildos y no al gobierno metropolitano. Por tanto, la flexibilización de la política fiscal o comercial se haría una realidad con la posibilidad de gestar la participación directa de los americanos en el gobierno metropolitano o con la formación de gobiernos provinciales autónomos, fenómenos que se dieron entre 1810 y 1815. 
EL FISCO SANTAFEREÑO EN TIEMPOS DE LA SOBERANÍA PROVINCIAL, 1810-1816

Es conocido que tras la abdicación de Fernando VII la crisis monárquica española tuvo un fuerte impacto en América, pues la conformación de la Junta Central de gobierno y el otorgamiento de representación a los criollos en ella fue asumida como un gesto con una doble significación para la elite criolla, en razón a que la misma se convertía en una oportunidad central para participar en la determinación de la política metropolitana, y así podrían llevar al gobierno metropolitano las propuestas para flexibilizar la política comercial y fiscal, pero la participación no era equitativa por el escaso número de representantes en América. Sin embargo, la oportunidad no fue desechada y se convirtió en un vehículo de partición materializado en las instrucciones que cada cabildo elaboró para que los diputados expusieran en la Junta, cuyo contenido se centró en el tema económico. Una de las poblaciones que se manifestó con mayor vehemencia a través de las representaciones enviadas por los cabildos para la Junta Central fue la del Socorro (Cabildo del Socorro, 2012), al igual que lo hizo Ignacio Herrera y Vergara (2007) ante Antonio Narváez, como diputado del reino de Nueva Granada ante la Junta Central de Sevilla. Ambos documentos propusieron la liberación del comercio con colonias extranjeras y países neutrales, la eliminación de los resguardos y del tributo indígena, la abolición del comercio de esclavos, la rebaja de los derechos eclesiásticos, la reducción de los agentes del fisco, la protección de la industria nativa a través del sistema aduanero, la eliminación de los estancos y la adopción de un fisco fundado en la contribución directa.

La oportunidad no se consolidó para Nueva Granada, pues el representante electo no pudo viajar debido a la disolución de la junta como producto del avance del ejército francés (Martínez, 2010a), y así se conformó el consejo de regencia, institución que enviaría a Antonio Villavicencio como encargado de mantener la calma en la inestable Nueva Granada, inquieta por los sucesos de Quito y Charcas. Villavicencio tenía como principal objetivo conformar juntas provinciales similares a las de la metrópoli, dependientes de una junta central con sede en Santafé, impulso que permitió la conformación de las mismas durante todo el año de 1810 (Martínez, 2007). Contrario a sus designios, algunas de las juntas no reconocieron la autoridad del Consejo de Regencia y se autoproclamaron depositarias del poder soberano.

Este marco permitió que la soberanía se resquebrajara en el centro de Nueva Granada ya que algunas villas pretendieron erigirse en provincias independientes. Santafé ambicionó convertirse en centro político y las provincias fieles a la regencia harían lo imposible por desconocer a sus 
pares autonomistas; la guerra interna se hizo inevitable (Martínez, 2010b). De esta manera, Santafé hizo frente a dos guerras: una contra el Congreso de las Provincias Unidas, culminada en 1814, y otra contra las fuerzas realistas del suroccidente y de Santa Marta.

El primer frente de guerra al que combatió Santafé se produjo ante la intención de las autoridades de la Junta Suprema de Gobierno para convertir a la capital en centro político del disuelto virreinato, convocando al Congreso Constituyente en julio de 1810, a lo cual se opuso Cartagena y Antioquia; finalmente este Congreso se instaló en diciembre con la participación de representantes de Santafé, Mariquita, Neiva, Socorro, Pamplona, Novita y Citara. Sin embargo, la aceptación de villas como provincias arruinó la posibilidad de unión; posteriormente se retiraron varias provincias de este primer experimento constitutivo. El Congreso se disolvió en febrero de 1811, lo que provocó la escisión soberana en dos agrupaciones (Cundinamarca y las Provincias Unidas) e hizo inminente la guerra civil (Martínez, 2010b).

El gobierno de Cundinamarca fue dirigido con mano firme por Antonio Nariño y estaba en contra del Congreso de las Provincias Unidas con sede en Tunja. Nariño organizó expediciones militares para anexar corregimientos a la jurisdicción de Santafé e inició la primera guerra civil en Nueva Granada durante el primer semestre de 1812. Posteriormente, la ofensiva fue tomada por el Congreso de Tunja que exigió la renuncia de Nariño al gozar de poderes dictatoriales en Santafé. Así, se produjo una nueva confrontación entre noviembre de 1812 y enero de 1813 , de la que saldría victoriosa la capital, lo que permitió a Nariño organizar una nueva expedición, en esta ocasión contra las fuerzas realistas del suroeste, la cual fracasó estrepitosamente. A pesar de la partida de Nariño, la paz no retornó a Santafé debido a que en 1814 el Congreso de las Provincias Unidas decidiría asaltar la capital una vez más para desconocer a Juan Bernardo Álvares, a quien Nariño había dejado el mando de la capital, campaña que esta vez fue exitosa para el bando invasor a la cabeza de Simón Bolívar. De esta forma la guerra reinó en Santafé entre 1812 y 1815, permanencia que afectó los objetivos para el diseño de la política fiscal.

Asumir la soberanía provincial por parte de la junta de gobierno y del colegio constituyente de Cundinamarca no sólo significó la guerra, sino también una oportunidad para que la elite criolla hiciera realidad el proyecto de flexibilizar la política fiscal y comercial, lo cual se llevó a cabo en 1810 al eliminarse el estanco del tabaco, los resguardos y el tributo indígena (Liévano, 1980), medidas pospuestas como producto de la necesidad de fondos para enfrentar la guerra, misma que se recrudecía por la negación de Bogotá para ceder las rentas de diezmos y de la Casa de Moneda al Congreso de las Provincias Unidas (Sosa, 2006). 
Contrario a las expectativas de los criollos, la guerra constante significó un aumento de la presión fiscal, como lo denota el restablecimiento de los gravámenes decretado en la Constitución de Cundinamarca de julio de 1812, la reconstrucción del estanco del tabaco y el incremento de sus precios en 1813 (Martínez, 2010c). Igualmente, el gobierno independiente recurrió con mayor constancia a los recursos eventuales y al crédito, como en el empréstito decretado por Nariño en 1813 por 300000 pesos, del cual se recaudaron 175000 pesos (Muñoz, 2010); ese mismo año se recaudó otro préstamo entre los comerciantes por 112000 pesos para restablecer el fondo de la Casa de Moneda y el préstamo por 133376 pesos, decretado por Bolívar un año después para llevar a cabo la campaña del norte (Muñoz, 2010). En el mismo sentido, el Congreso tomó todo el fondo de diezmos para el gasto gubernamental (Congreso de las Provincias Unidas, 1989a) e intentó restablecer totalmente el orden fiscal colonial para hacer frente a la expedición de Morillo al reconstituir el tribunal mayor de cuentas, los estancos y el cargo de intendente de Hacienda para los gobernadores de provincia (Congreso de las Provincias Unidas, 1989b).

La guerra no sólo generó la crisis institucional y la adopción de una política fiscal errática, también afectó profundamente las actividades económicas del centro, como lo manifiestan las cifras de los remates de diezmos que reportan el estado de la producción agrícola, mismas que registraron una pendiente de regresión lineal de menos 12401 pesos entre 1810 y 1819, al igual que la producción minera, que registró una pendiente de regresión lineal de menos 19025 pesos en los rendimientos de amonedación en Santafé. Factores estos que componen el cuadro de descenso de $0.2 \%$ anual en el PIB per cápita (Kalmanovitz, 2010).

La guerra, el desorden administrativo y la crisis económica afectaron de forma radical el fisco santafereño. A escala global se registró una reducción de 57\% del promedio de los ingresos ordinarios entre 1810 y 1814 respecto al registrado entre 1800 y 1809 , a lo cual se sumó una marcada tendencia a la baja con una pendiente de menos 54142 pesos. Por otra parte, la guerra con el Congreso de las Provincias Unidas significó que varias de las cajas que antes enviaban sus sobrantes a la capital dejaran de hacerlo; a modo de ilustración, se pudo constatar que para 1814 tan sólo se recibieron fondos de Neiva y Honda por 914 pesos en total.

La composición del ingreso también cambió de forma dramática, ya que los ingresos eventuales pasaron a ser el primer renglón con $26 \%$ del total; los estancos llegarían sólo a 16\% tras su eliminación y fallida reconstrucción entre 1810 y 1812; los impuestos a la minería y a la agricultura sumaron 17\% cada uno, y los gravámenes comerciales tan sólo 13\%. Como si ello fuese poco, todos y cada uno de los ingresos ordinarios registraron pendientes negativas. 
La guerra y el desorden político también hicieron variar la composición del egreso, en la que el gasto militar empezó a ganar terreno en la participación global con $45 \%$ y con una pendiente de 5731 pesos, mientras que el gasto civil, a pesar de reportar $51 \%$, presentó una marcada tendencia a la baja; obviamente el pago de obligaciones crediticias también se elevó, mientras las remisiones a otras cajas se deterioraban paso a paso.

En este contexto, es preciso concluir que para 1810 los objetivos de la política fiscal buscaron promover la eliminación de las restricciones a la producción y al comercio, por ello se eliminaron varios de los antiguos impuestos coloniales. A pesar de ello, el inicio de la guerra contra el Congreso de las Provincia Unidas y contra las provincias fieles a la Regencia hizo necesario dejar tales objetivos en un segundo plano, pues los esfuerzos deberían estar concentrados en el gasto militar, ante lo cual se decidió echar marcha atrás frente a las reformas esgrimidas dos años antes. Los resultados no fueron los esperados, ya que la guerra, el desorden administrativo y la decadencia de las actividades económicas dieron como resultado un mediocre margen de ingreso incapaz de hacer frente a las obligaciones de gobierno, por lo que se hizo recurrente el uso del crédito y de los recursos eventuales.

En este panorama, en términos fiscales, no se podía esperar más que un elevado protagonismo del déficit, el cual llegó en promedio a una suma mayor de 86000 pesos anuales entre 1811 y 1814. Una burocracia confusa que consumía $51 \%$ del recaudo y que se hacía cada vez más débil debido a la tendente disminución de la inversión de fondos para su mantenimiento y un ejército voraz que no quedaba satisfecho ante el aumento anual de la inversión para su sostenimiento, tendrían que hacer frente a la reconquista comandada por un vasto ejército organizado en la metrópoli.

\section{EL FISCO SANTAFEREÑO DURANTE LA RECONQUISTA, 1815-1819}

Mientras en Nueva Granada se libraban batallas entre las provincias independientes y las realistas, en España la victoria de Wellington y la firma del tratado de Valencay restituyeron a Fernando VII en el trono español, quien entró triunfante a Madrid en mayo de 1814 y decretó el 4 de mayo el restablecimiento de la monarquía absoluta y la nulidad de todas las medidas expedidas por las Cortes de Cádiz. Por supuesto, una de las principales preocupaciones de la corona y de los comerciantes de Cádiz era estabilizar la situación política americana, razón por la que se instauró la Comisión de Remplazos como ente encargado para financiar la expedición militar que llevó a cabo la empresa (Quintana, 2006), misma que zarpó el 17 de febrero de 1815 bajo la comandancia de Pablo Morillo. Media década de refor- 
mas fiscales apresuradas y de guerras entre independentistas y regentistas dejaron a Nueva Granada con una fuerza militar incapaz de enfrentar a la expedición española, lo que permitió que Morillo y sus fuerzas establecieran el poder regio desde Cartagena hasta Santafé en tan sólo diez meses, y un año después en la totalidad del sur neogranadino:

Una vez en posesión de todos los puertos, Morillo organizó la pacificación del interior: para el Chocó salió el teniente coronel Julián Bayer; para Antioquia y el Cauca, el capitán Francisco Warleta, y para el río Magdalena, el coronel Donato Santa Cruz. Por otro lado, de Venezuela venía el coronel Sebastián de la Calzada rumbo a Pamplona, y después se encaminó a Tunja y Santa Fe. En pos de Warleta salió de Cartagena el general Miguel de Latorre; pasó por Ocaña, donde ya no encontró ningún obstáculo y llegó a Santa Fe el 6 de mayo de 1816. El 15 de febrero se encargó de la ciudad de Cartagena el virrey don Francisco de Montalvo, y Morillo se dirigió a Santa Fe, a donde llegó el 26 de mayo. Los rescoldos de libertad comenzaron a apagarse con la derrota de García Rovira en el páramo de Cachiri, entre el 21 y 22 de febrero de 1816 (Barriga, 1998, pp. 234-235).

Los rezagos del ejército neogranadino se dirigieron a Casanare donde se encontraban algunas guerrillas dispersas de Piar, Mariño y Páez, única región que se mantuvo convulsionada hasta 1818 , al término del mandato del virrey Montalvo. Así, en el año de 1816 existieron 24 enfrentamientos bélicos debido a la campaña de Morrillo; para 1817 y 1818 sólo se registraron doce enfrentamientos en Nueva Granada (Avendaño y Torres, 2010).

La necesidad de restablecer el orden colonial en territorios que vivieron independientes a la corona, en un contexto de guerra permanente con focos de inestabilidad en el oriente y los llanos venezolanos, obligaron a que las instituciones establecidas por Morillo fuesen cada vez más severas para el restablecimiento del orden; como resultado, se restituyó el Tribunal de Inquisición para acabar con las publicaciones prohibidas, el Consejo de Purificación encargado de excluir de la administración real a los funcionarios partidarios de la independencia, la Junta de Secuestros encargada de decomisar los bienes de los opositores al rey y el Tribunal Permanente de Guerra responsable del juicio y ejecución de un gran número de dirigentes políticos independentistas; instituciones que establecieron lo que se conoce como el régimen del terror, el cual se mantuvo después de la partida de Morillo hacia Caracas en 1817 bajo la dirección de Pascual Enrile y de Juan Sámano como virrey desde 1818.

Los resultados de la campaña de reconquista muestran que para 1818 el centro de Nueva Granada era una de las regiones donde la reorganización del fisco surtió un mayor efecto como lo demostró la recomposición de las factorías de tabaco de Ambalema, Pie de Cuesta, Pore y Llano 
Grande (Montalvo, 1989). Igualmente, Santafé logró -aunque de forma intermitente-recomponer los flujos del situado, ya que envió 36000 pesos en 1817, 60000 pesos a Cartagena para los gastos del ejército comandado por Morillo en Venezuela y 50000 pesos para hacer frente a la campaña contra los patriotas de los llanos (Montalvo, 1989). Respecto a lo administrativo y lo judicial, se logró reinstaurar el Tribunal Mayor de Cuentas y la Real Audiencia en la capital virreinal.

A pesar de estos avances, los fondos no fueron suficientes para mantener el gasto militar, puesto que de los 1300424 pesos invertidos por el centro de Nueva Granada para el sostenimiento del ejército expedicionario, $53 \%$ provenía de los secuestros, contribuciones, donativos y multas; $34 \%$ fue tomado de los sobrantes de las Cajas Reales y 13\% provino de empréstitos forzosos (Perilla, 2012). Por lo tanto, es lícito afirmar que el avance en la reconstrucción de la administración y del fisco tuvo un alcance limitado e hizo necesario el recurso a ingresos eventuales para el mantenimiento de la burocracia y el ejército, lo que generó un aumento del recaudo frente al periodo de la soberanía provincial, sin lograr reconstituir las fuentes de dinero ordinarias o los promedios de ingresos entre 1800 y 1809.

Los principales objetivos de las políticas fiscales se centraron en la reorganización del aparato tributario colonial con el fin de mantener al ejército y recomponer la estructura administrativa. El análisis de las cifras de ingreso muestra el relativo éxito de las medidas implantadas. En términos globales el promedio de los ingresos subió y la pendiente de la ecuación de la recta muestra un valor de 251346 pesos entre 1816 y 1818; sin embargo, dichos resultados estaban sustentados en los ingresos provenientes de los secuestros y remates de bienes confiscados a partidarios del gobierno independentista, ramo que junto a otros eventuales sumó $27 \%$ del total colectado, los ingresos provenientes de la Iglesia aportaron $20 \%$ con tendencia al alza debido a la enajenación de fondos de diezmos en calidad de reintegro, los gravámenes comerciales subían y aportaban 19\% del total gracias a la sobretasa de 3\% impuesta por Morillo sobre la alcabala (Muñoz, 2012). Los estancos también mostraron un buen desempeño a pesar de la imposibilidad del restablecimiento total del monopolio del aguardiente (Montalvo, 1989). Los dos novenos reales, como contribución sobre la producción agrícola, también tuvieron una tendencia al alza participando con 5.4\% del total del ingreso. Los impuestos a la minería aportaron 3.4\% y también mostraron una tendencia al alza a pesar del deterioro del fondo disponible en la Casa de Moneda para la compra de oro (Montalvo, 1989). Los descuentos a empleados sumaron 1.8\% del total; el tributo, 1.2\%, y el crédito, $1.18 \%$, todos con tendencia al alza.

Los realistas también restablecieron el flujo de remisiones de otras tesorerías hacia la capital, aunque con tendencia a la baja reflejada en la 
pendiente de menos 21870 pesos, debido a que el virrey Montalvo desvió los situados de nuevo hacia la costa atlántica en contraposición a las medidas adoptadas por Morillo, las cuales apuntaban a enviar todos los sobrantes a la capital para tenerlos disponibles en la tesorería del ejército expedicionario (Montalvo, 1989). En este sentido, la composición de los ingresos no era la misma que la registrada entre 1800 y 1809, pues ganaba preponderancia el recurso a fondos eventuales y los estancos no retomaron su protagonismo, así como tampoco las remisiones de otras tesorerías.

La composición del egreso muestra en primer lugar el administrativo con $63 \%$ del total con una pendiente de 5754 pesos, muy lejana a la del gasto militar que se encontraba en 20878 pesos con una participación de $29 \%$ del total. Así, el gasto militar crecía de forma más acelerada que el burocrático. Las remisiones a otras cajas llegaron a sólo $6 \%$ del total, los gastos eclesiásticos, $2 \%$, y el servicio de deuda a $0.1 \%$. La dinámica y composición del gasto también devela el éxito relativo en el cumplimiento de los objetivos de la política fiscal, debido a que fue necesario dar prelación al gasto militar frente al civil creciendo a tasas más aceleradas, el servicio de deuda fue descuidado y las remisiones a otras tesorerías no llegaban a cubrir el área de influencia que ocupaba Santafé para la última década del siglo de las luces.

Aunque el déficit no apareció y el crédito no tuvo una participación preponderante debido al recurso de recaudos abusivos por parte del gobierno realista; la ambición de la empresa por recomponer la administración civil y ganar la guerra en un corto lapso hizo que los fondos no fuesen suficientes, por lo que dejó sin recursos valiosos a las fuerzas armadas en momentos en que la guerra contra los patriotas no había sido totalmente ganada, fenómeno que hacía cada vez más insostenible el gobierno colonial, como lo demuestran las tensiones que se generaban entre el ejército y la burocracia civil por la escasez de fondos para el mantenimiento de las tropas, las cuales se encontraban en una total precariedad para 1819 (Barreiro, 1989). Economía, ejército y gobierno débiles constituyeron el panorama para la configuración de la nueva república con sede en Bogotá.

\section{Fiscalidad bOgOtana En la RepÚblica de Colombia, 1819-1830}

Para agosto de 1819 las tropas comandadas por Simón Bolívar tomaron Bogotá y sellaron su total independencia de España. Sin embargo, la guerra no terminaría y Bogotá desde diciembre de 1819 tendría que consolidarse como fuente para el financiamiento de los ejércitos que seguirían luchando hasta 1824. La prolongación de la guerra hizo que variara el principio para la administración de los recursos, de esta manera se establecen tres 
periodos: el primero, comprendido entre 1819 y 1824, de manejo centralizado de los ingresos; el segundo, entre 1824 y 1826, estuvo marcado por un espíritu de federalismo moderado en la medida en que los fondos de correos, aduanas y tabacos fueron manejados de forma autónoma por los gobernadores departamentales; por último, entre 1828 y 1830 se vivió un periodo de autonomía regional en el manejo de los recursos, en el que Bogotá controló los pertenecientes a Nueva Granada; Caracas, los de la antigua intendencia de Venezuela, y Quito, los de la extinguida Audiencia.

Entre 1819 y 1830 Bogotá fue la tesorería principal del recién fundado departamento de Cundinamarca con jurisdicción en las provincias de Neiva, Antioquia, Mariquita y Cundinamarca, posición que le permitió centralizar los excedentes de las cuatro cajas y hacer frente a los déficits de cada una de ellas. De igual modo, se constituyó en la región en donde se concentraron los poderes ejecutivo, legislativo, judicial y el militar.

El poder legislativo estuvo a cargo del orden fiscal y la determinación de la estructura tributaria, cuyas principales reformas cambiaron poco el sistema colonial en términos impositivos, ya que los aranceles aduaneros aumentaron en tres ocasiones y los impuestos eclesiásticos se mantuvieron iguales. Se intentó abolir el estanco del aguardiente al establecer el sistema de patentes en 1821, renaciendo sólo cinco años después; el tabaco no tuvo mayores cambios; la alcabala se eliminó para bienes domésticos, pero aumentó a 2.5\% para bienes raíces y mercancías importadas, restableciéndose en 1828 sobre toda mercadería con una tasa de 15\%; el tributo indígena se abolió en el Congreso de Cúcuta y fue restablecido en la dictadura de Bolívar (Pinto, 2011); mientras que la contribución directa fue un total fracaso debido a varios factores, a saber: $a$ ) la precariedad del catastro, $b$ ) la fuerte oposición de la elite terrateniente y $c$ ) los vicios de recaudo ante la designación de los párrocos como funcionarios encargados de recolectar la información para su liquidación (Pinto, 2014).

El mantenimiento de la guerra, las reformas administrativas constantes y una política fiscal vacilante marcaron al fisco de la naciente república y de su capital, que se vio afectada también por los desórdenes internos. El descontento se hizo sentir en Venezuela desde 1826, debido a la escasa representatividad de los orientales en el Congreso y por la distancia que los separaba de Bogotá, lo que hizo que las determinaciones del gobierno central sufriesen una gran demora a la hora de solventar los problemas locales (Bushnell, 1985). En Ecuador la tensión se presentaba como producto de la poca atención del gobierno central para solucionar la crisis de la manufactura de la sierra Centro-Norte y al desconocer las demandas de Guayaquil para la trasformación del régimen aduanero, a lo cual se sumó la guerra de 1828 contra Perú debido a su interés por anexar la costa pacífica (Bushnell, 1985). En términos económicos, Bogotá también sufrió las 
consecuencias de diez años de guerra e inestabilidad institucional como lo demuestra la débil recuperación de la producción agrícola (Brungardt, 1983) y la agudización de la crisis de los rendimientos mineros, latente en la pendiente de regresión lineal de la serie de amonedación de la casa capitalina, cálculo que llegó a registrar menos 593012 pesos (Torres, 2012). Estos factores afectaron profundamente el fisco capitalino.

En términos globales la pendiente muestra que los ingresos ordinarios tendieron a caer ya que registraron un valor de menos 221674 pesos. Como en el periodo colonial, los estancos volvieron a ser la principal fuente de ingresos al aportar 43\% del recaudo con tendencia al alza. Los impuestos mineros aportaron 16\%; sin embargo, tendieron a caer debido a la lenta recuperación de tal actividad. Los impuestos eclesiásticos sumaron $14 \%$ con tendencia a la baja. Por otra parte, a pesar de su eliminación en 1821 la alcabala reportó $12 \%$ del recaudo, pero mostró rendimientos positivos gracias a su reconstitución en 1828 con una alícuota alta. Los novenos aportaron $5.6 \%$ con rendimientos que reflejan una leve recuperación del sector agrario; la contribución directa sólo aportó 3.6\%; la masa común, 2.5\%, y los tributos indígenas, tras su derogación en 1821 y acelerada reconstitución en 1828 , sólo aportaron $0.6 \%$. Así, la caída de la serie global obedeció a un deterioro de todos los rubros de ingreso, a excepción de los monopolios.

Las remisiones de otras tesorerías muestran la reconstitución de los flujos del situado ya que incluyeron regiones como Honda, Antioquia, Cartagena, Riohacha, Santa Marta, Caracas y Quito; sin embargo, como producto de las reformas de 1824 y 1828, las regiones más distantes dejaron de hacer remisiones y otorgaron plena autonomía a los departamentos, primero para la realización de gastos extraordinarios y luego liberándolos de la obligación para enviar fondos y cuentas a la capital. En tal contexto, la tendencia al alza por este rubro fue muy inferior a las expectativas del gobierno central, ya que registró únicamente una pendiente de 156 pesos.

La dinámica de ingreso hizo poco sostenible los gastos, que representaban en términos globales una pendiente de 935098 pesos, fundamentalmente compuestos por $57 \%$ de erogaciones militares, $29 \%$ en las asignaciones de la administración civil y $12 \%$ destinado a las demandas de la deuda nacional, todos ellos con tendencia al alza con mayor proporción en el plano militar. La baja de los ingresos y el acelerado crecimiento del gasto dejaron como resultado un elevado déficit que sumó un promedio anual de 1328027 pesos, lo cual sólo pudo suplirse por medio del crédito interno y externo.

Un proceso de reconfiguración fiscal entorpecido por el desorden político, la guerra y la inestabilidad económica, sumado a una constante 
presión para el incremento de los gastos civiles, militares y de servicio de deuda, hizo necesario el recurso al crédito externo por parte de la república. La deuda externa de Colombia comporta las obligaciones contraídas por Zea en 1822 y las contraídas con la casa comercial Goldschmidt por 4750000 libras en 1824, suma cuyo 36.96\% fue invertido en el cubrimiento de deudas anteriores e intereses y amortizaciones adelantadas al nuevo préstamo; el resto se distribuyó de la siguiente forma: 39\% en deuda interna, 29\% para cubrir los déficits de tesorerías provinciales, $12 \%$ en gastos de guerra, $7 \%$ en gastos de la administración civil, $4.6 \%$ en la manutención del Congreso, 3.3\% en las Casa de Moneda, 2.7\% para pago de atrasos a los cosecheros de tabaco y $0.1 \%$ en los fletes de conducción de algunos caudales (Pinto, 2011).

Bogotá era el centro de una república empeñada, cuya deuda ascendía a 56736228 pesos, donde 73\% correspondía a deuda externa, $21.6 \%$ a deuda interna reconocida y dividida entre Colombia, Venezuela y Ecuador en 1838, y 5\% a deuda pagadera flotante en 1832 (Comisión de Crédito Nacional, 2010; Junguito, 1995; República de Colombia, 2010).

Desde luego los objetivos del fisco bogotano cambiaron de acuerdo con las condiciones de la guerra. En una primera instancia se optó por una administración centralizada y leves reformas al sistema impositivo para ganar la guerra contra España entre 1819 y 1824, lo cual se logró. Una vez consolidada la victoria se propuso convertir al fisco en instrumento para la promoción de las actividades productivas y la consolidación de la estructura administrativa, tras lo que se dio libertad a los gobiernos departamentales para efectuar gastos extraordinarios y recurrir al crédito externo. Ni la consolidación de la estructura administrativa ni la promoción de la economía fueron posibles pues la mayor parte de los rubros del crédito externo fueron usados en el cubrimiento de obligaciones crediticias de distintas tesorerías, haciendo de nuevo recurrente el déficit para el pago de la burocracia y el ejército. En consecuencia, las regiones exigieron total autonomía, modelo administrativo que fue adoptado en 1828 junto con el restablecimiento de los impuestos coloniales, con el fin de mantener el orden interno, lo cual tampoco fue suficiente al hacer naufragar el proyecto republicano.

El fisco de Bogotá es el reflejo de toda la república: bajos ingresos, crecidos gastos, déficit y deudas, en un contexto de desorden político interno, inestabilidad institucional, guerra y crisis económica. Después de 20 años de lucha independentista el Estado no lograba consolidar el monopolio militar ni fiscal y la elite neogranadina no podía gozar de la eliminación de las trabas fiscales coloniales ni de una absoluta libertad comercial. Así, Bogotá como eje central de la república fue incapaz de evitar la separación de Ecuador y Venezuela. 


\section{CONCLUSIONES}

Desde 1780 hasta 1830, la guerra externa e interna provocó cambios en los objetivos primordiales del fisco en Santafé y Bogotá. Entre 1780 y 1809 la política fiscal buscó hacer partícipe a la capital virreinal en el proyecto de conformación del Estado fiscal militar español, siendo primordial para sus gastos la inversión en la administración civil, la remisión de fondos para la consolidación del sistema de defensa del sur del Caribe o con destino a la metrópoli, razón por la cual se optó por una estructura administrativa de carácter centralizado y un aumento de la presión fiscal con base en la reorganización de los monopolios y del sistema de cobros de los restantes recaudos.

Desde 1810 hasta 1814, y como producto de la caída de España en manos del dominio francés, el ejercicio de la soberanía fiscal recayó en manos de la elite criolla, y entre 1810 y 1812 se optó por una política impositiva flexible a favor del mejoramiento de las actividades productivas, y así se permitió la eliminación de varios impuestos coloniales; sin embargo, el inicio de la guerra interna reorientó los esfuerzos al mantenimiento del aparato bélico, lo que generó la reconstitución de gravámenes antes eliminados. Entre 1815 y 1819 el reconstruido gobierno realista instauró como prioridades del fisco la recomposición de la estructura administrativa y la victoria total sobre los restos del ejército republicano, con base en una estructura impositiva similar a la existente entre 1780 y 1809 .

En el periodo de 1819 a 1830 los objetivos de la política fiscal pasaron del aseguramiento de la victoria contra España, con base en una estructura administrativa centralizada y una política impositiva con leves trasformaciones, a un modelo que buscó consolidar el Estado a través del mantenimiento de la burocracia, el ejército y la promoción de las actividades productivas con fondos provenientes del crédito externo y una relativa autonomía regional en el manejo del gasto. Por último, entre 1828 y 1830, ante las insurrecciones regionales, el fisco se convirtió nuevamente en pieza clave para el mantenimiento del orden político por medio del gasto militar; por ello se restablecieron los gravámenes coloniales eliminados en 1821 y se otorgó plena autonomía a las regiones en términos fiscales.

Un primer acercamiento a los resultados fiscales de tales objetivos, estructura administrativa y política impositiva, puede efectuarse al analizar la serie de ingresos ordinarios, es decir, de aquellos provenientes de actividades económicas internas. Tal ejercicio mostró, a través de las pendientes de regresión lineal, que de 1780 a 1799 y de 1816 a 1818 el ingreso tuvo tendencias positivas, mientras que de 1800 a 1809 , de 1810 a 1814 y de 1820 a 1829 fueron negativas. En términos de egreso, las pendientes muestran un comportamiento similar, a excepción del periodo 1820-1829 en donde el ingreso crece, siendo constante el déficit (véase gráfica 2). 


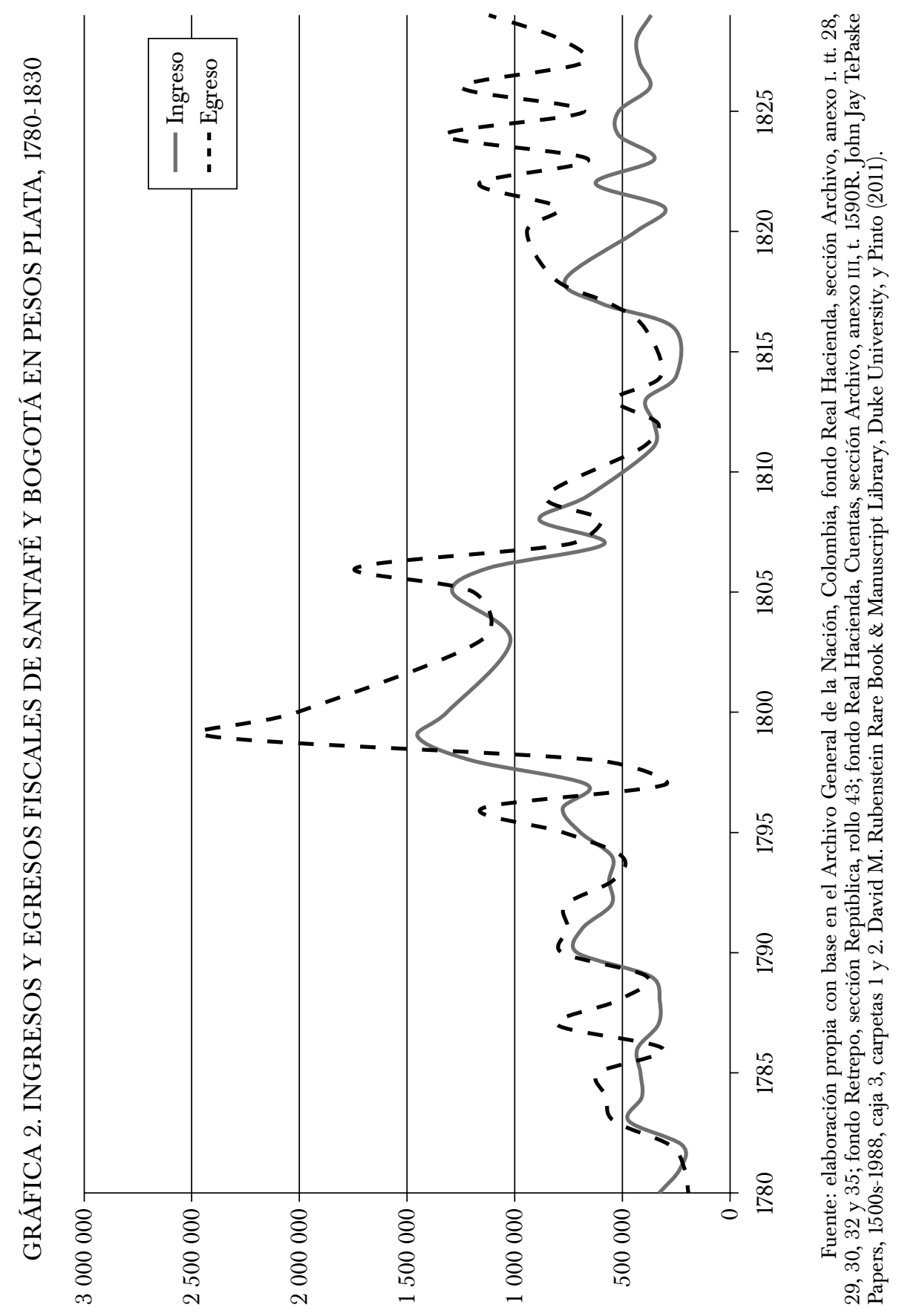


Sin embargo, para llegar a conclusiones certeras sobre los resultados de la política fiscal es necesario no sólo analizar la dinámica global, sino también la composición del ingreso y el egreso como producto de la estabilidad política y la dinámica económica. Entre 1780 y 1799 el gobierno colonial, con base en los buenos rendimientos de la economía neogranadina y la paz interna, logró consolidar los monopolios como fuente principal de ingresos y convertir a Santafé en centro de acopio del excedente fiscal, con una marcada tendencia al alza para la segunda década. Sin embargo, entre 1800 y 1809 la reanudación de la guerra con Inglaterra y Francia generó el cierre de puertos, con ello se afectaron los flujos comerciales, la actividad agrícola y minera haciendo caer los rendimientos de los principales rubros de ingreso. Entre 1810 y 1814 las autoridades de la primera república sufrieron la caída de todos los ramos de ingreso debido al desorden administrativo y el deterioro del sector productivo a consecuencia de la guerra. Entre 1816 y 1818 el reconstituido gobierno colonial mejoró los rendimientos de los ingresos ordinarios; sin embargo, no igualaron los ingresos coloniales, por lo que fue necesario el recurso a ingresos eventuales. Entre 1820 y 1829 el gobierno republicano mejoró los rendimientos de la reconquista, pero la mayor parte de sus ramos develan tendencias a la baja como producto del desorden interno, la prolongación de la guerra con España y la lenta recuperación de las actividades económicas, teniendo que recurrir en grandes proporciones al crédito (véase gráfica 3).

La composición de los gastos también permite analizar los resultados de la política fiscal. Santafé durante el periodo colonial ocupó la mayor parte de sus ingresos en la consolidación de la administración de su jurisdicción, además de enviar fondos con regularidad a otras cajas, especialmente a aquellas que eran pieza clave del sistema de defensa al sur del Caribe (véase gráfica 4). Esta situación cambió para el periodo de 1810 a 1814, ya que los escasos ingresos y la guerra provocaron la eliminación de los situados y una drástica caída en el gasto de la administración civil. Para el periodo de la reconquista, la burocracia consumió la mayor parte de los fondos; sin embargo, la pendiente muestra un acelerado aumento del gasto militar, lo cual no fue suficiente para hacer frente a las demandas del ejército expedicionario. El último periodo muestra una total concentración de las erogaciones en el sector militar dificultando la consolidación del sistema administrativo.

Entre 1780 y 1830, la política fiscal de Santafé y Bogotá buscó tímidamente la modernización del sistema impositivo a favor de iniciar la transición de un Estado patrimonial a uno fiscal. Por ello se intentó vigilar y administrar de forma centralizada los ingresos y los egresos, así como promover el recaudo de fondos provenientes de actividades económicas privadas y no sólo con base en los rendimientos de los recursos patrimoniales 


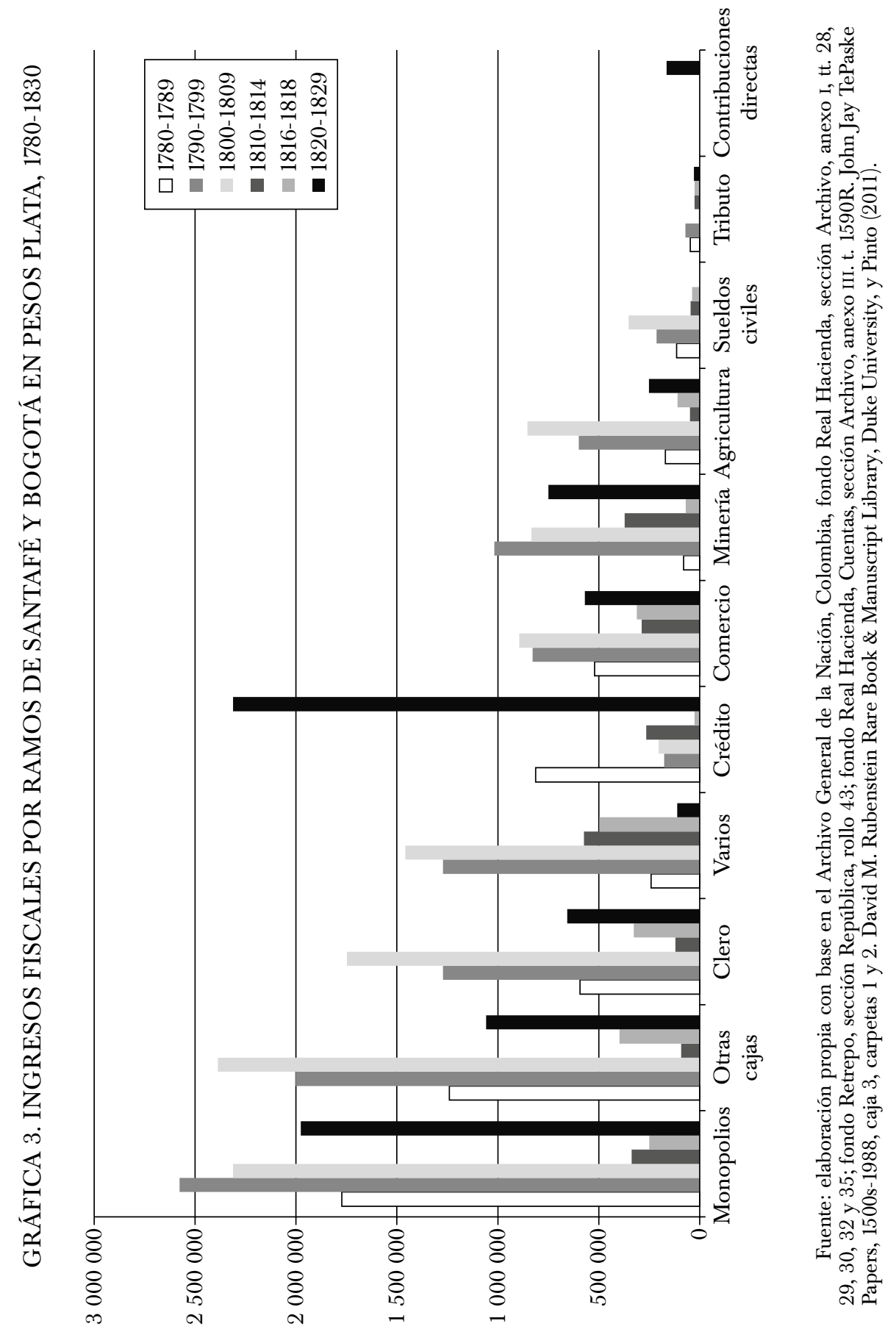




\section{GRÁFICA 4. EGRESOS FISCALES POR RAMOS DE SANTAFÉ Y BOGOTÁ EN PESOS PLATA, 1780-1830}

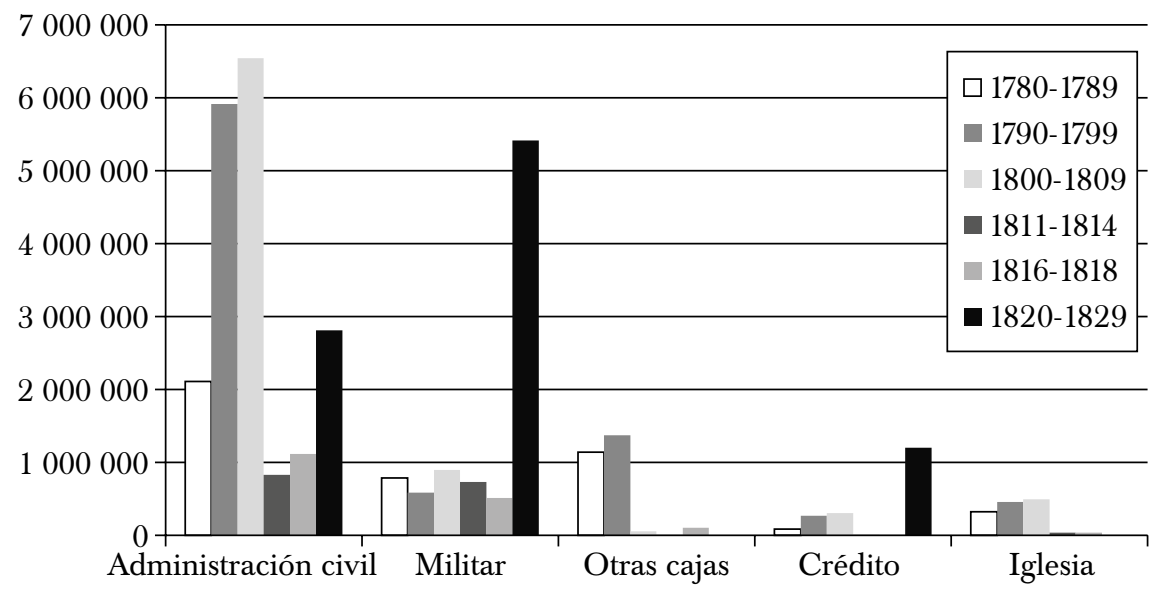

Fuente: elaboración propia con base en el Archivo General de la Nación, Colombia, fondo Real Hacienda, sección Archivo, anexo I, tt. 28, 29, 30, 32 y 35; fondo Retrepo, sección República, rollo 43; fondo Real Hacienda, Cuentas, sección Archivo, anexo III, t. 1590R. John Jay TePaske Papers, 1500s-1988, caja 3, carpetas 1 y 2. David M. Rubenstein Rare Book \& Manuscript Library, Duke University, y Pinto (2011).

del Estado. La guerra fue el principal escollo para tal modernización, en un primer momento el deterioro de las actividades productivas hizo caer el ingreso de las arcas capitalinas entre 1800 y 1809. Después de ello, los criollos a la cabeza del gobierno autónomo intentaron eliminar los monopolios y las trabas al comercio, pero la confrontación con otras provincias y la corona provocó la reconstitución de los gravámenes eliminados. Las autoridades realistas que lograron retomar Santafé en 1816 intentaron volver a consolidar los logros alcanzados entre 1780 y 1809 , lo cual fue imposible, pues el elevado gasto militar obligó a recurrir a exacciones de carácter abusivo. Por último, entre 1819 y 1830 las escasas reformas propuestas por el Congreso chocaron con la prolongación de la guerra contra España hasta 1824 y con el desorden interno desde 1826, lo que generó la reconcentración en el gasto militar y debilitó la formación de una burocracia sólida que vigilara de forma directa el recaudo, además de sufrir la reducción de los ingresos ordinarios que continuaron comandados por los monopolios, recurriendo al crédito. La guerra, la crisis económica y el desorden administrativo impidieron la modernización del fisco santafereño entre 1780 y 1830 , caracterizado por su carácter patrimonial. 


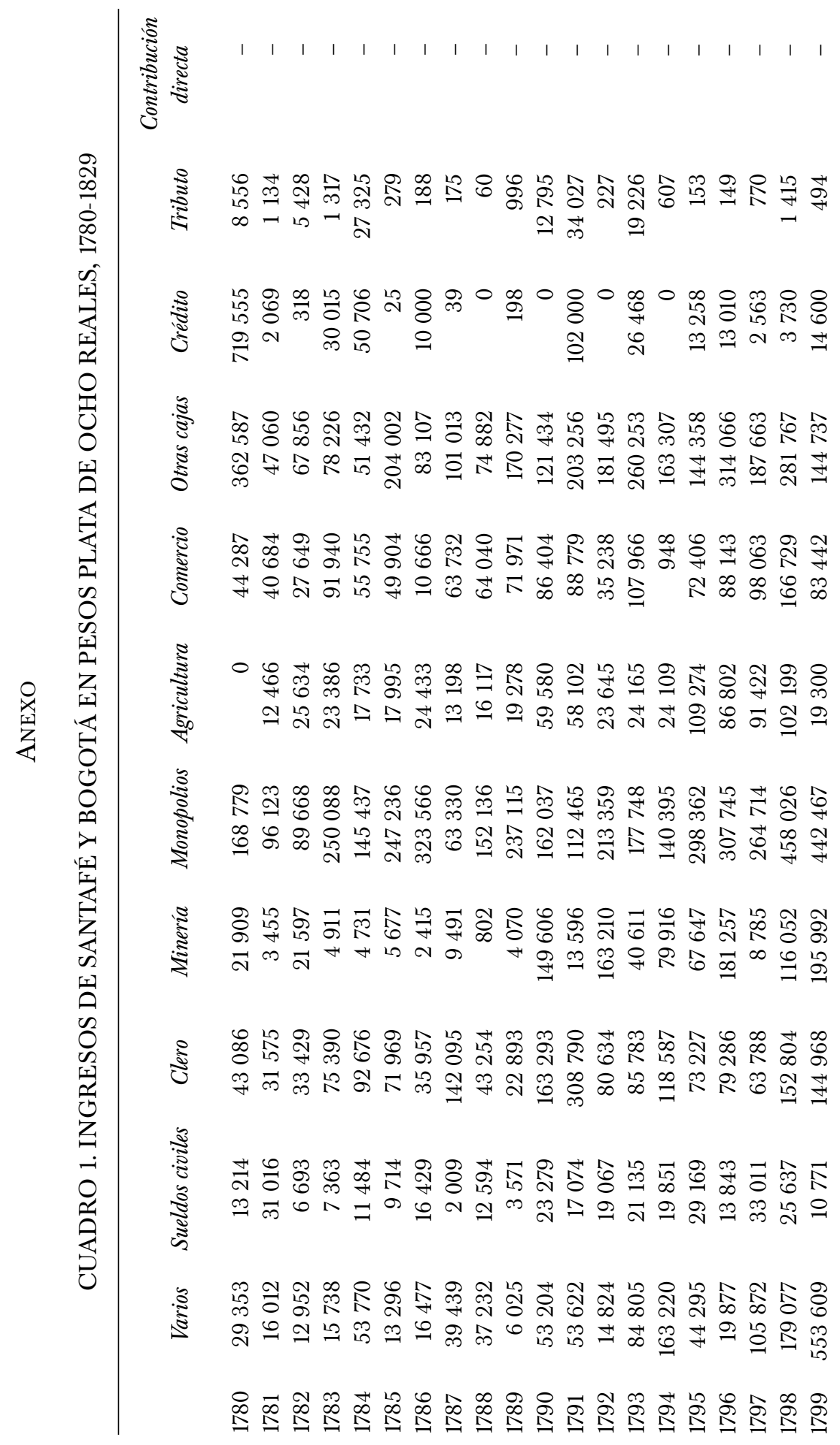




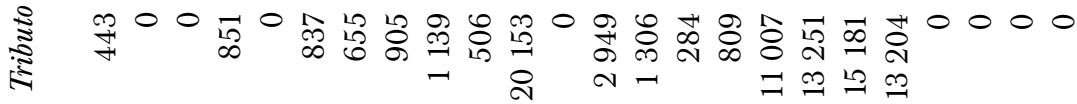

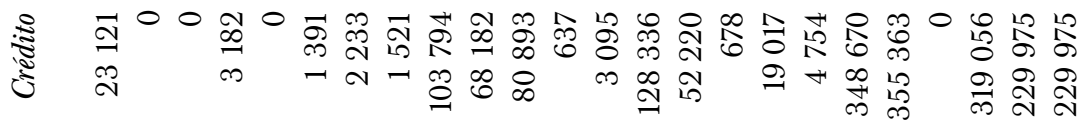

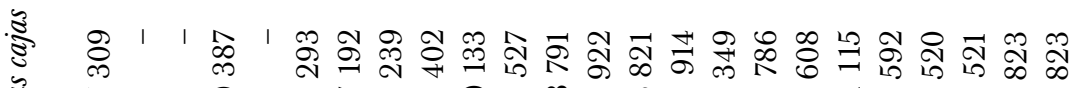

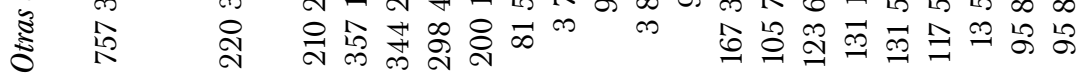

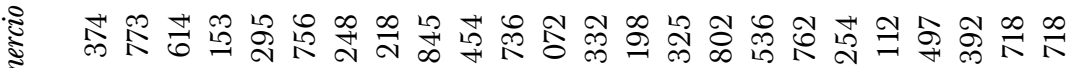

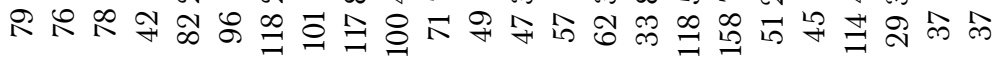

:

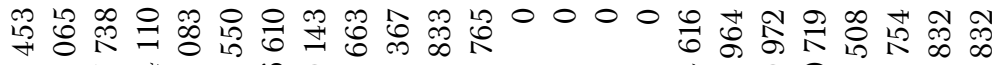

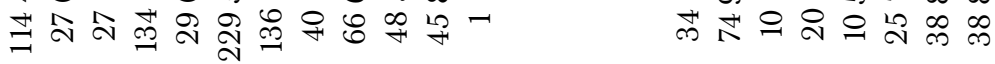

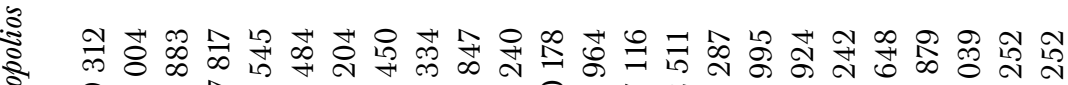

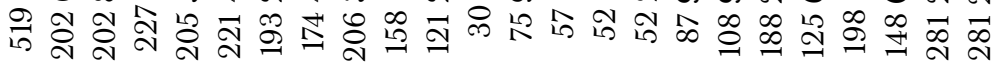

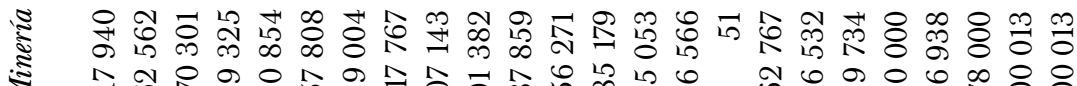

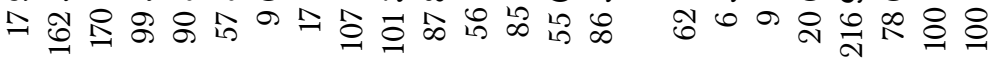

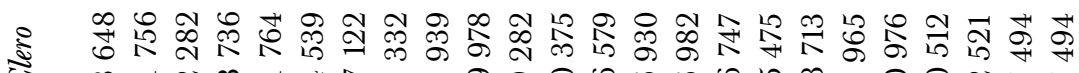

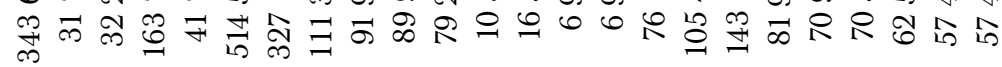

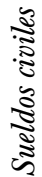

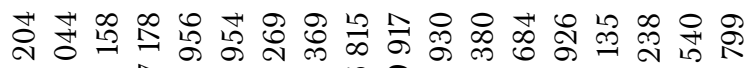

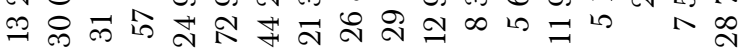

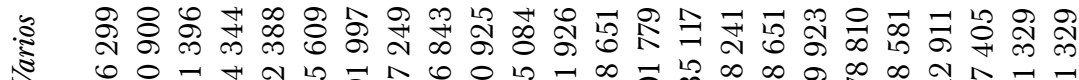

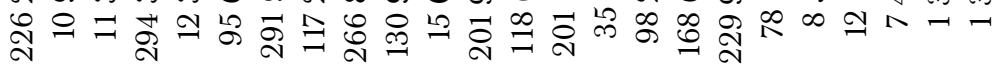

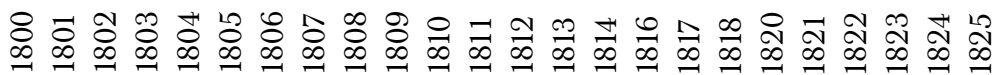




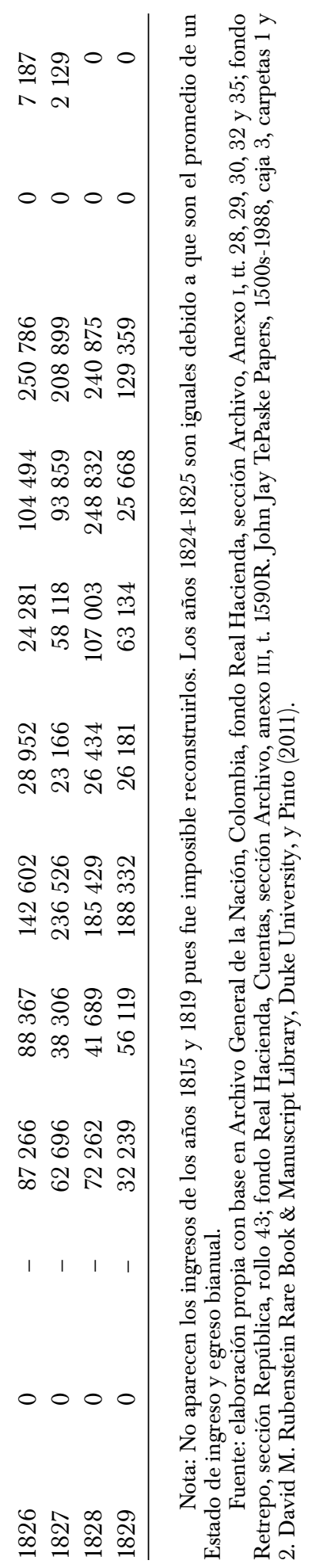


CUADRO 2. GASTOS DE SANTAFÉ Y BOGOTÁ EN PESOS PLATA DE OCHO REALES, 1780-1830

\begin{tabular}{|c|c|c|c|c|c|}
\hline & $\begin{array}{c}\text { Administración } \\
\text { civil }\end{array}$ & Otras cajas & Militar & Iglesia & Crédito \\
\hline 1780 & 70266 & 67762 & 27274 & 28540 & 36 \\
\hline 1781 & 127173 & 34113 & 27895 & 22188 & - \\
\hline 1782 & 62699 & 193679 & 18262 & 7139 & - \\
\hline 1783 & 199465 & 237630 & 33011 & 55704 & 15512 \\
\hline 1784 & 246799 & 17946 & 223592 & 65000 & 21539 \\
\hline 1785 & 200162 & 268887 & 109857 & 13695 & 18398 \\
\hline 1786 & 250431 & - & 47519 & 688 & 13540 \\
\hline 1787 & 444797 & 175202 & 133054 & 44644 & 5109 \\
\hline 1788 & 181367 & 107994 & 162854 & 60422 & 11570 \\
\hline 1789 & 323267 & 39426 & - & 23640 & - \\
\hline 1790 & 243349 & 109327 & 127604 & 210690 & 91341 \\
\hline 1791 & 585183 & 80383 & 3946 & 3999 & 80000 \\
\hline 1792 & 697074 & 43941 & 5909 & 3362 & 13326 \\
\hline 1793 & 438989 & 32268 & 21665 & 50623 & - \\
\hline 1794 & 332965 & 96509 & 294 & 71148 & 1102 \\
\hline 1795 & 262301 & 326334 & 113035 & 37852 & 36292 \\
\hline 1796 & 441806 & 578708 & 95352 & 23693 & 11396 \\
\hline 1797 & 227960 & 47364 & 2374 & 5986 & 14603 \\
\hline 1798 & 425572 & 47804 & 110913 & 24653 & 9382 \\
\hline 1799 & 2260057 & 6381 & 106924 & 28000 & 12031 \\
\hline 1800 & 1769571 & 2614 & 105395 & 23934 & 107968 \\
\hline 1803 & 1026559 & 3970 & 103527 & 20249 & 0 \\
\hline 1805 & 710595 & 7672 & 148304 & 308449 & 17100 \\
\hline 1806 & 1572103 & 3544 & 125956 & 35699 & 30 \\
\hline 1807 & 466748 & 4251 & 126596 & 42920 & 104822 \\
\hline 1808 & 310038 & 27596 & 140572 & 50649 & 68051 \\
\hline 1809 & 686205 & 2335 & 143329 & 14362 & 7138 \\
\hline 1811 & 197987 & 175 & 201879 & 10121 & 0 \\
\hline 1812 & 216749 & - & 107258 & 9653 & 250 \\
\hline 1813 & 278747 & 110 & 246333 & 7014 & 2049 \\
\hline 1814 & 133912 & - & 174625 & 9059 & 2996 \\
\hline 1816 & 334727 & 60000 & 1991 & 1227 & 0 \\
\hline 1817 & 433105 & 39595 & $75 \quad 168$ & 9014 & 322 \\
\hline 1818 & 346236 & 4115 & 431747 & 25581 & 4368 \\
\hline 1820 & 391000 & - & 552296 & - & 0 \\
\hline 1821 & 248561 & - & 498619 & - & 52750 \\
\hline
\end{tabular}




\begin{tabular}{rcrcrr} 
& $\begin{array}{c}\text { Administración } \\
\text { civil }\end{array}$ & Otras cajas & Militar & Iglesia & Crédito \\
& & & & & \\
1822 & 365690 & - & 615268 & - & 183600 \\
1823 & 209336 & - & 414548 & - & 35528 \\
1824 & 426921 & - & 718288 & - & 184412 \\
1825 & 212735 & - & 357924 & - & 106842 \\
1826 & 151623 & - & 982669 & - & 112797 \\
1827 & 199009 & - & 318341 & - & 171600 \\
1828 & 364455 & - & 392076 & - & 33183 \\
1829 & 238362 & - & 564362 & - & 317581 \\
\hline
\end{tabular}

Nota: los años 1801, 1802, 1804, 1815 y 1819 no se pudieron reconstruir.

Fuente: elaboración propia con base en el Archivo General de la Nación, Colombia, fondo Real Hacienda, sección Archivo, anexo I, tt. 28, 29, 30, 32 y 35; fondo Retrepo, sección República, rollo 43; fondo Real Hacienda, Cuentas, sección Archivo, anexo III, t. 1590R. John Jay TePaske Papers, 1500s-1988, caja 3, carpetas 1 y 2. David M. Rubenstein Rare Book \& Manuscript Library, Duke University, y Pinto (2011).

\section{LISTA DE REFERENCIAS}

Alves, A. y Sánchez Santiró, E. (2012). Introducción: Guerra y fiscalidad en Iberoamérica colonial. En A. Alves y E. SÁnchez SANTiRó (eds.), Guerra y fiscalidad en Iberoamérica colonial (pp. 25-37). México: Editorial Universidad Federal de Juiz de Fora/Instituto de Investigaciones Dr. José María Luis Mora.

ANGulo, M. (2000). La Hacienda española en el siglo XVIII. Las rentas provinciales. Madrid: Centro de Estudios Políticos y Constitucionales.

ARDANT, G. (1975). Financial policy and economic infrastructure of modern states and nations. En C. Tilly (ed.), The formation of nation state in Western Europe (pp. 164243). Nueva Jersey: Princeton University Press.

ARÉVALO, D. (2011). Guerra y fiscalidad en el tránsito del virreinato a la república: Nueva Granada, 1796-1821. Jahrbuch für Geschichte Lateinamerikas, 48, 31-56.

Arévalo, D., Fresneda, O., Chaparro, G. y Rodríguez, O. (2009). La contraloría y Bogotá: 80 años de historia. Bogotá: Contraloría de Bogotá.

Avendaño, J. y TORRes, J. (2010). Los teatros de la guerra: cartografía, demografía y economía: 1811-1824 (Documento de trabajo del Grupo de Investigación en Historia Económica y Social del Departamento de Historia). Colombia: Universidad Nacional de Colombia.

Barbier, J. A. (1980). Pennisular finance and colonial trade: The dilemma of Charles IV's Spain. Journal of Latin American Studies, 12(1), 21-37.

BARreiro, J. M. (1989). Oficio número 107, reservado, del coronel Barreiro al virrey Sámano, sobre las necesidades y miseria que sufren las tropas en vísperas de em- 
prender una dura campaña, situación que es la causa principal de las deserciones. Sogamoso, 23 de marzo de 1819. En L. LóPEZ (ed.), Los ejércitos del rey 1818-1819 (t. 2, p. 31). Bogotá: Academia Colombiana de Historia.

BARRIGA, F. (1998). Finanzas de nuestra primera independencia: apuntes económicos, financieros y numismáticos. Bogotá: Academia Colombiana de Historia.

BoHórquez, J. (2009). Más para entretener la miseria que despertar la codicia: los frutos del comercio y los mercados imperiales durante el nacimiento del liberalismo. Nueva Granada, 1780-1810. Anuario Colombiano de Historia Social y de la Cultura, 36(1), 21-56.

BoHÓRQUez, J. (2014). Luces para la economía. Libros y discursos de economía política en el Atlántico español durante la era de las revoluciones (Nueva Granada, 1780-1811). Bogotá: Instituto Colombiano de Antropología e Historia.

Brewer, J. (1990). The sinews of power: War, money, and the English State, 1688-1783. Cambridge: Harvard University Press.

Brungardt, M. (1983). Tithe production and patterns of economic change in central Colombia, 1764-1833 (Tesis de doctorado). University of Texas, Austin.

Bushnell, D. (1985). El régimen de Santander en la Gran Colombia. Bogotá: El Áncora Editores.

CABILdo Del Socorro. (2012). Instrucción del Socorro al diputado de la Junta Central gubernativa de España e Indias, en la cual aluden la formación de una Constitución. En I. VANEGAS (ed.), El constitucionalismo revolucionario, 1809-1815 (t. 1, pp. 46-49). Bucaramanga: Universidad Industrial de Santander.

Campillo y Cosio, J. (1784). Nuevo sistema de gobierno económico para la América: con los males y desafíos que le causa el que hoy tiene, de los que participa copiosamente España; y remedios universales para que la primera tenga considerables ventajas, y la segunda mayores intereses. Madrid: Imprenta de Benito Cano.

Carrillo, T. (1998). Proyecto cuentas nacionales de Venezuela: 1800-1830. Caracas: Banco Central de Venezuela.

Comín, F. y Yun-Casalilla, B. (2012). Spain: From composite monarchy to nation state, 1492-1914. En F. Comín, B. Yun-Casalilla y P. O’Obrien (eds.), The rise of fiscal states. A global history, 1500-1914 (pp. 233-266). Nueva York: Cambridge University Press.

Comisión de Crédito Nacional (2010). Informe de labores, 1832. En F. BARRiga, Finanzas de nuestra segunda independencia. Apuntes económicos, financieros y numismáti$\cos$ (Disco compacto anexo). Bogotá: Universidad de los Andes/Academia Colombiana de Historia.

Congreso de las Provincias Unidas de la Nueva Granada (1989a). Ley sobre diezmos. En G. Hernández (ed.), Congreso de las provincias unidas (t. 1, pp. 180183). Bogotá: Academia Colombiana de Historia.

Congreso de las Provincias Unidas de la Nueva Granada (1989b). Ley sobre el establecimiento de una contaduría general de Hacienda. En G. Hernández (ed.), 
Am. Lat. Hist. Econ., año 22, núm. 3, septiembre-diciembre, 2015, pp. 7-43

Congreso de las Provincias Unidas (t. 1, pp. 103-111). Bogotá: Academia Colombiana de Historia.

DíAz, C. (2013). Hacienda pública en tiempos de guerra: la Caja Real de Santafé de Bogotá durante la reconquista de la Nueva Granada, 1816-1818. Fronteras de la Historia, 18(1), 129-164.

DiEU, J. P. (2009). La Nueva Planta en su contexto. Las reformas del aparato del Estado en el reinado de Felipe V. Manuscrits, 18, 113-169.

FRIEDE, J. (1981). Rebelión comunera de 1781: documentos (t. 1). Bogotá: Editorial Linotipia de Bolívar.

GonZÁlez, A. (2008). El Estado fiscal militar, una reflexión alternativa. Memoria y civilización. Anuario de historia de la Universidad de Navarra, 11, 271-295.

HALPERIN, T. (2005). Guerra y finanzas en los orígenes del Estado argentino, 1791-1850. Buenos Aires: Prometeo Libros.

Herrera y Vergara, I. De (2007). Reflexiones que hace un americano imparcial al diputado de este Reino de Granada para que las tenga presentes en su delicada misión, $1^{\circ}$ de septiembre de 1809. En A. Almarza y A. Martínez (eds.), Instrucciones para los diputados del Nuevo Reino de Granada y Venezuela ante la Junta Central Gubernativa de España y las Indias (pp. 59-86). Bucaramanga: Universidad Industrial de Santander.

Irigoin, A. y Grafe, R. (2008). Bargaining for absolutism: A Spanish path to nationstate and empire building. Hispanic American Historical Review, 88(2), 173-209.

IRIGOIN, A. y GRAFE, R. (2012). Absolutismo negociado: la trayectoria hispana en la formación del Estado y el imperio. En C. MARichal y J. VON Grafenstein (eds.), El secreto del imperio español: los situados coloniales en el siglo XVIII (pp. 295-340). México: El Colegio de México/Instituto de Investigaciones Dr. José María Luis Mora.

JARA, A. (2011). El imperio español en América (1700-1820). Santiago de Chile: Editorial Sudamericana.

JARAmillo, J. (2007). La economía del virreinato, 1740-1810. En J. A. OCAMPO (ed.), Historia económica de Colombia (pp. 61-100). Bogotá: Planeta.

Junguito, R. (1995). La deuda externa en el siglo XIX. Cien años de incumplimiento. Bogotá: Tercer Mundo Editores.

Kalmanovitz, S. (2010). Nueva historia económica de Colombia. Bogotá: Universidad Jorge Tadeo Lozano/Taurus.

KLEIN, H. (1973). Structure and profitability of royal finance in the viceroyalty of the Rio de la Plata in 1790. The Hispanic American Historical Review, 53(3), 440-469.

KLEIN, H. (1994). Las finanzas americanas del imperio español: 1680-1809. México: Instituto de Investigaciones Dr. José María Luis Mora.

LiÉVANO, I. (1980). Los grandes conflictos sociales y económicos de nuestra historia (t. 2). Bogotá: Ediciones Tercer Mundo.

LYNCH, J. (1983). Las revoluciones hispanomericanas, 1808-18126. Barcelona: Ariel.

MARICHAL, C. (1999). La bancarrota del virreinato, Nueva España y las finanzas del imperio español, 1780-1810. México: Fondo de Cultura Económica. 
Marichal, C. y Carmagnani, M. (2001). From colonial fiscal regime to liberal financial order, 1750-1912. En M. BoRDO y R. CORTÉS-CONDE (eds.), Transferring wealth and power from the Old to the New World: Monetary and fiscal institutions in the 17th through the 19th centuries (pp. 284-326). Nueva York: Cambridge University Press.

Martínez, A. (2007). La reasunción de la soberanía por las juntas de notables en el Nuevo Reino de Granada. En M. CHUST (ed.), La eclosión juntera del mundo hispano (pp. 286-333). México: Fondo de Cultura Económica/El Colegio de México.

Martínez, A. (2010a). La agenda liberal temprana en la Nueva Granada, 1800-1850. Bucaramanga: Universidad Industrial de Santander.

Martínez, A. (2010b). La vida política. En E. Posada y A. Meisel (eds.), Colombia: crisis imperial e independencia (pp. 37-86). Madrid: Fundación MAPFRE/Santillana Editores.

Martínez, A. (2010c). La agenda liberal de los estados provinciales de la Nueva Granada, 1811-1815. En P. PÉREZ e I. Simón (eds.), El liberalismo, la creación de la ciudadanía y los Estados nacionales occidentales en el espacio Atlántico, 1787-1880 (pp. 125162). Bucaramanga: Universidad de Alcalá/Universidad Industrial de Santander.

Meisel, A. (2011). Crecimiento, mestizaje y presión fiscal en el virreinato de la Nueva Granada, 1760-1800. Cuadernos de Historia Económica y Empresarial, 28, 1-97.

Montalvo, F. (1989). Instrucción sobre el estado en que deja el Nuevo Reino de Granada el excelentísimo señor don Francisco de Montalvo, en 30 de enero de 1818, a su sucesor el excelentísimo señor don Juan de Sámano. En G. Colmenares, Relaciones de mando e informes de los gobernantes de la Nueva Granada (t. 3, pp. 193-336). Bogotá: Fondo de Promoción de la Cultura del Banco Popular.

MuÑoz, E. (2010). La estructura del ingreso y del gasto en la Caja Real de Santafé, 1803-1815. Anuario Colombiano de Historia Social y de la Cultura, 37(2), 45-85.

MuÑoz, E. (2012). Independencia y actividad económica. Tendencias cuantitativas en la renta de alcabalas de Santa Fe, virreinato de la Nueva Granada, 1780-1821. En H. Bonilla (ed.), Consecuencias económicas de la independencia (pp. 14-44). Bogotá: Universidad Nacional de Colombia.

NARIÑO, A. (1990). Ensayo sobre un nuevo plan de administración en el Nuevo Reino de Granada. En G. Hernández (ed.), Archivo Nariño, 1795-1810 (t. 2, pp. 207-227). Bogotá: Presidencia de la República.

Ocampo, J. (1999). El proceso ideológico de la emancipación en Colombia. Bogotá: Planeta.

Perilla, A. (2012). Financiamiento de los ejércitos en la guerra de Independencia de Colombia. En H. Bonilla (ed.), Consecuencias económicas de la independencia (pp. 119-136). Bogotá: Universidad Nacional de Colombia.

Pinto, J. (2011). Finanzas de la República de Colombia, 1819-1830 (Tesis de maestría). Universidad Nacional de Colombia, Colombia.

PinTo, J. (2014). Los orígenes del impuesto directo y progresivo en América Latina. Historia y sociedad, 24, 53-77.

Poмbo, J. I. DE (1965). Informe del Real Consulado de Cartagena de Indias, 1800. En S. E. Ortiz (ed.), Escritos de dos economistas coloniales: don Antonio de Narváez y la Torre y don José Ignacio de Pombo (pp. 13-47). Bogotá: Banco de la República. 
Quintana, G. (2006). Pablo Morillo: general de dos mundos. Madrid: Planeta.

República de Colombia (2010). Decreto del 7 de febrero de 1838. En F. BarRiga, Finanzas de nuestra segunda independencia. Apuntes económicos, financieros y numismáticos (pp. 911-920). Bogotá: Universidad de los Andes/Academia Colombiana de Historia.

Rodríguez, O. (1983). Anotaciones al funcionamiento de la Real Hacienda en el Nuevo Reino de Granada. S. XVIII. Anuario Colombiano de Historia Social y de la Cultura, $11,71-88$.

SCHnerb, R. (1973). Technique fiscale et partis pris sociaux l'impôt foncier en France depuis la Révolutio. En J. Bouvier y J. WolfF (eds.), Deux siècles de fiscalité française, XIX-XX siècle (pp. 79-104). París: Mouton Éditeur.

Schumpeter, J. (2000). La crisis del Estado fiscal. Revista Española de Control Externo, 2(5), 147-192.

SosA, G. (2006). Representación e independencia, 1810-1816. Bogotá: Instituto Colombiano de Antropología e Historia.

Storrs, C. (2009). The Fiscal-Military State in the "long" eighteenth century. En C. STORRs (ed.), The fiscal-military state in eighteenth-century Europe: Essays in honor of $P$. G. M. Dickson (pp. 1-22). Burlington: Ashgate Publishing, Ltd.

Torres, J. (2012). La minería neogranadina en la trayectoria de la colonia a la república, 1780-1839. En H. Bonilla (ed.), Consecuencias económicas de la independencia (pp. 45-76). Bogotá: Universidad Nacional de Colombia.

Torres, J. (2013). Minería y moneda en el nuevo reino de Granada. El desempeño económico en la segunda mitad del siglo XVIII. Bogotá: Instituto Colombiano de Antropología e Historia.

Torres, R. (2007). Possibilities and limits: Testing the fiscal-military state in the anglospanish war of 1779-1783. En R. TORREs (ed.), War, state and development. fiscalmilitary states in eighteenth century (pp. 437-460). Navarra: EUNSA.

WALLERSTEIN, I. (1984). El moderno sistema mundial. El mercantilismo y la consolidación de la economía-mundo europea, 1600-1750 (t. 2). Madrid: Siglo XXI Editores.

Yun-Casalilla, B. (2012). Introduction: The rise of the fiscal state in Eurasia from a global, comparative and transnational perspective. En F. COMín, B. YUn-CASALILla y P. O'Obrien (eds.), The rise of fiscal states. A global history, 1500-1914 (pp. 1-35). Nueva York: Cambridge University Press.

\section{OTRAS FUENTES}

Archivo General de la Nación, Bogotá, Colombia.

John Jay TePaske Papers. 1500s-1988. Caja 3, carpetas 1 y 2. David M. Rubenstein Rare Book \& Manuscript Library, Duke University. 